ARGONNE NATIONAL LABORATORY

P. O. Box 299

Lemont, Illinois

PERFORMANCE AND POTENTIAL

OF

NATURAL CIRCULATION BOILING REACTORS

by

W. S. Flinn and M. Petrick

Reactor Engineering Division

October, 1957

Operated by The University of Chicago under

Contract W-31-109-eng-38 


\section{DISCLAIMER}

This report was prepared as an account of work sponsored by an agency of the United States Government. Neither the United States Government nor any agency Thereof, nor any of their employees, makes any warranty, express or implied, or assumes any legal liability or responsibility for the accuracy, completeness, or usefulness of any information, apparatus, product, or process disclosed, or represents that its use would not infringe privately owned rights. Reference herein to any specific commercial product, process, or service by trade name, trademark, manufacturer, or otherwise does not necessarily constitute or imply its endorsement, recommendation, or favoring by the United States Government or any agency thereof. The views and opinions of authors expressed herein do not necessarily state or reflect those of the United States Government or any agency thereof. 


\section{DISCLAIMER}

Portions of this document may be illegible in electronic image products. Images are produced from the best available original document. 
TABLE OF CONTENTS

Page

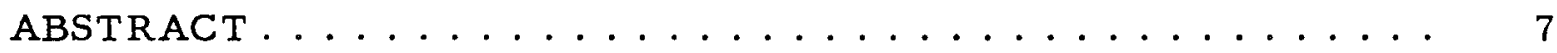

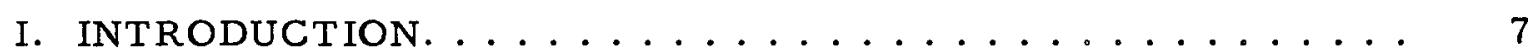

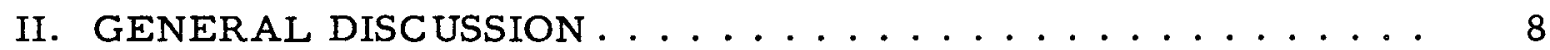

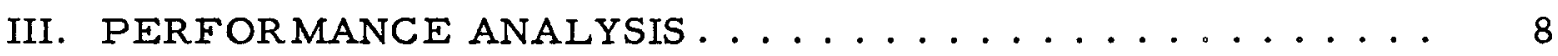

IV. GENERAL DESIGN CONSIDERATIONS ........... 10

A. Pressure ...................... 10

B. Geometry ..................... 11

C. Burnout ................... 12

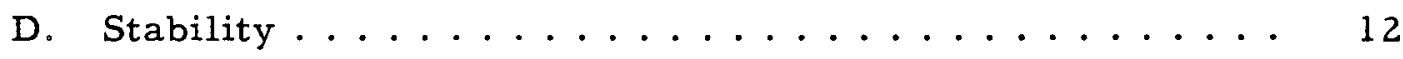

E. Efficiency................. 13

v. CONCLUSIONS ...................... 13

APPENDIX: METHOD OF ANALYSIS ............ 43 
NOMENCLAT URE
A Flow Cross-Sectional Area
$f t^{2}$
d Hydraulic Diameter $\left(\mathrm{d}_{\mathrm{C}}=\mathrm{S} / 6\right)$
$f t$
f Single-Phase Isothermal Friction Factor
g Acceleration Due to Gravity
$\mathrm{ft} / \sec ^{2}$
H External Loss Factor Expressed as Number of Velocity Heads $\left(\mathrm{V}^{2} / 2 \mathrm{~g}\right)$
L Length
$P \quad$ System Pressure
Q'' Power Density of Core Coolant
R Two-Phase Friction Factor Multiplier
$r \quad$ Acceleration Multiplier
$\mathrm{ft}^{3} / 1 \mathrm{~b}$
S Channel Spacing $\left(S=6 \mathrm{~d}_{\mathrm{C}}\right)$
in.
T Temperature
$\mathrm{V} \quad$ Water Velocity at the inception of boiling
$\mathrm{ft} / \mathrm{sec}$
$\begin{array}{ll}v_{\mathbf{s}} & \text { Slip Ratio (Local Velocity of Steam/Local } \\ v_{w} & \text { Velocity of Water) }\end{array}$
$\mathbf{x} \quad$ Steam Weight Flow Fraction
lb steam/lb mixture
$\alpha \quad$ Steam Volume Fraction
$\mathrm{ft}^{3}$ steam $/ \mathrm{ft}^{3}$ mixture
$\rho$ Density
$1 \mathrm{~b} / \mathrm{ft}^{3}$

\section{SUBSCRIPTS}

$B \quad$ Net Boiling

NB Non Net Boiling

C Core

D Downcomer

e Core exit

w Saturated water

Ri Riser

s Steam

t Total (core + riser)

m Make-up 
LIST OF FIGURES

No.

Title

Page

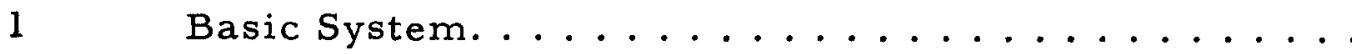

15

(2-10) Effect of Pressure and Height of Riser on Performance of Natural Circulation Boiling Reactors for:

$2 \quad \mathrm{~S}=0.24$ in.; $\bar{\alpha}_{\mathrm{C}}\left(\rho_{\mathrm{w}}-\rho_{\mathrm{S}}\right)=2.2 \mathrm{lb} / \mathrm{ft}^{3} ; \mathrm{T}_{\mathrm{m}}=100 \mathrm{~F} \ldots 16$

$3 \quad \mathrm{~S}=0.48 \mathrm{in} . ; \bar{\alpha}_{\mathrm{C}}\left(\rho_{\mathrm{w}}-\rho_{\mathrm{S}}\right)=2.2 \mathrm{lb} / \mathrm{ft}^{3} ; \mathrm{T}_{\mathrm{m}}=100 \mathrm{~F} \ldots . .17$

$4 \quad \mathrm{~S}=0.72 \mathrm{in} . ; \bar{\alpha}_{\mathrm{C}}\left(\rho_{\mathrm{w}}-\rho_{\mathrm{S}}\right)=2.2 \mathrm{lb} / \mathrm{ft}^{3} ; \mathrm{T}_{\mathrm{m}}=100 \mathrm{~F} \ldots 18$

$5 \quad \mathrm{~S}=0.24$ in.; $\bar{\alpha}_{\mathrm{C}}\left(\rho_{\mathrm{w}}-\rho_{\mathrm{s}}\right)=4.4 \mathrm{lb} / \mathrm{ft}^{3} ; \mathrm{T}_{\mathrm{m}}=100 \mathrm{~F} \ldots . .19$

$6 \quad \mathrm{~S}=0.48$ in.; $\bar{\alpha}_{\mathrm{C}}\left(\rho_{\mathrm{w}}-\rho_{\mathrm{s}}\right)=4.4 \mathrm{lb} / \mathrm{ft}^{3} ; \mathrm{T}_{\mathrm{m}}=100 \mathrm{~F} \ldots .20$

$7 \quad \mathrm{~S}=0.72$ in.; $\bar{\alpha}_{\mathrm{C}}\left(\rho_{\mathrm{w}}-\rho_{\mathrm{S}}\right)=4.4 \mathrm{lb} / \mathrm{ft}^{3} ; \mathrm{T}_{\mathrm{m}}=100 \mathrm{~F} \ldots 21$

$8 \quad \mathrm{~S}=0.24$ in.; $\bar{\alpha}_{\mathrm{C}}\left(\rho_{\mathrm{W}}-\rho_{\mathrm{S}}\right)=8.8 \mathrm{lb} / \mathrm{ft}^{3} ; \mathrm{T}_{\mathrm{m}}=100 \mathrm{~F} \ldots . .22$

$9 \quad S=0.48$ in.; $\bar{\alpha}_{C}\left(\rho_{\mathrm{w}}-\rho_{\mathrm{S}}\right)=8.8 \mathrm{lb} / \mathrm{ft}^{3} ; \mathrm{T}_{\mathrm{m}}=100 \mathrm{~F} \ldots 23$

$10 \quad \mathrm{~S}=0.72 \mathrm{in} . ; \bar{\alpha}_{\mathrm{C}}\left(\rho_{\mathrm{w}}-\rho_{\mathrm{S}}\right)=8.8 \mathrm{lb} / \mathrm{ft}^{3} ; \mathrm{T}_{\mathrm{m}}=100 \mathrm{~F} \ldots 24$

(11-25) Effect of Riser Height and Exit Steam Volume Fraction on Performance of Natural Circulation Boiling

Reactors for:

11

$\mathrm{S}=0.12$ in.;

$\mathrm{P}=600 \mathrm{lb} / \mathrm{in}^{2} \ldots \ldots \ldots \ldots . \ldots 25$

12

$\mathrm{S}=0.25 \mathrm{in} . ;$

$P=600 \mathrm{lb} /$ in. $^{2} \ldots \ldots \ldots \ldots 26$

13

$S=0.5$ in.;

$\mathrm{P}=600 \mathrm{lb} / \mathrm{in}^{2} \ldots \ldots \ldots \ldots . \ldots 27$

14

$S=0.12$ in.;

$\mathrm{P}=1000 \mathrm{lb} /$ in. $^{2}$

28

15

$S=0.25$ in.;

$\mathrm{P}=1000$

$1 b / i n$.

29

16

$S=0.5$ in.;

$P=1000$

$\mathrm{lb} / \mathrm{in}^{2}$

30

17

$S=0.12$ in.;

$\mathrm{P}=1500$

$1 \mathrm{~b} / \mathrm{in}^{2}$.

31

18

$S=0.25$ in.;

$\mathrm{P}=1500$

32

19

$S=0.5$ in.;

$\mathrm{P}=1500 \mathrm{lb} / \mathrm{in}^{2}$

20

$S=0.12$ in.;

$\mathrm{P}=2000 \mathrm{lb} / \mathrm{in} .^{2}$

34

21

$S=0.25$ in.;

$\mathrm{P}=2000 \mathrm{lb} / \mathrm{in}^{2}$. 35

22

$\mathrm{S}=0.5$ in.;

$P=2000$ 36

23

$S=0.12$ in.;

$\mathrm{P}=2500 \mathrm{lb} / \mathrm{in}$. 


\section{LIST OF FIGURES}

No.

Title

Page

26 Effect of External Resistance on Performance of Natural Circulation Boiling Reactors, $\mathrm{P}=1500 \mathrm{lb} / \mathrm{in}^{2} ; \mathrm{L}_{\mathrm{C}}=8 \mathrm{ft} ; \mathrm{d}_{\mathrm{C}}=0.04 \mathrm{ft} ; \mathrm{L}_{\mathrm{Ri}}=50 \mathrm{ft} \ldots . .40$

27 Change of True Coolant Density Deviation with Pressure for $\bar{\alpha}_{\mathrm{C}}\left(\rho_{\mathrm{W}}-\rho_{\mathrm{S}}\right)=2.2 \mathrm{lb} / \mathrm{ft}^{3} \ldots \ldots \ldots . \ldots . \ldots . \ldots 1$

28 Effect of Temperature and Pressure on Rankine Cycle

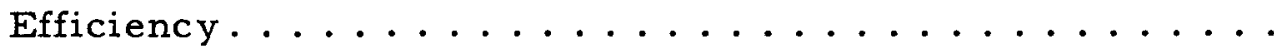

29 Effect of Make-up Water Temperature on Reactor

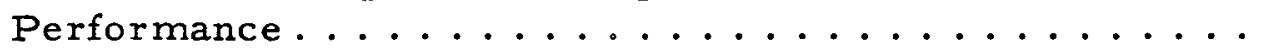

30 Average Two-Phase Friction Factor Multiplier $(\overline{\mathrm{R}})$ vs Exit Steam Volume Fraction $\left(\alpha_{\mathrm{e}}\right) \ldots \ldots \ldots . \ldots . \ldots . \ldots 45$

31 Local Two-Phase Friction Factor (R) vs Steam Volume Fraction $(\alpha) \ldots \ldots \ldots \ldots \ldots \ldots \ldots . \ldots \ldots$

32 Slip Ratio $\left(v_{s} / v_{w}\right)$ vs Water Velocity $\left(v_{w}\right) \ldots \ldots 45$ 
6 


\title{
7 \\ PERFORMANCE AND POTENTIAL \\ OF \\ NATURAL CIRCULATION BOILING REACTORS
}

by

W. S. Flinn and M. Petrick

\begin{abstract}
A parametric study of the potential and performance of natural circulation boiling nuclear reactors is presented. Analyses are based on engineering data and correlation extrapolations obtained from boiling studies at Argonne. Graphs are used extensively to show inter relationships of power density, system pressure, average core coolant density, core height, riser height, channel hydraulic diameter, recirculation flow rate, and exit steam volume fraction. Interesting aspects of reactor design and their effects on performance are discussed briefly.
\end{abstract}

\section{INTRODUCTION}

Although there is considerable interest in boiling water reactors, little is known about their design parameters, let alone their future potential. Therefore, a study has been initiated at Argonne to evaluate the capabilities of natural circulation reactors utilizing information presently available. The approach used is based primarily upon steady-state engineering aspects with nuclear considerations being secondary. This report represents a preliminary summary of a portion of this study.

An attempt is made to show the potential of natural circulation boiling reactors by presenting performance parameters and by discussing interesting and significant facets of design.

This study should not be construed as a comprehensive analysis of boiling reactors, since no attempt has been made to evaluate all parameter combinations or reactor cycle variations. Basically, the purpose of this report is to show that the potential of natural circulation boiling reactors is not as limited as many believe. It is hoped that the information presented will be of value in determining desirable avenues of boiling reactor design and development. 
II. GENERAL DISCUSSION

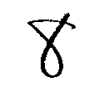

A basic problem of reactor design is to obtain the maximum amount of power from the reactor core. With boiling reactors it is usually desirable to generate this power with a minimum amount of steam volume in the core. Large quantities of steam represent a loss in moderation, usually a loss in reactivity, and reduce maximum power density due to stability and burnout considerations.

The importance of low steam volume in the core depends upon the type of reactor. The effect on moderation and reactivity is less for heavy water reactors than it is for light water reactors. However, the basic heat flux limitations, and many of the stability problems, are the same for both light and heavy water reactors. Although the properties of light water were used in the calculations, the hydrodynamic and thermodynamic properties of light and heavy water are sufficiently similar to give a fairly representative picture of the relative effects of such parameters as pressure, geometry, etc., on heavy water reactor performance.

The calculation methods and analytical procedures used are discussed in the Appendix. All calculations were checked on the IBM-650 computer.

This report is concerned primarily with the simple direct cycle shown in Fig. 1. The steam generated in the core flows directly to the turbine, after which it is condensed and pumped back into the reactor vessel at a temperature of about $100 \mathrm{~F}$.

Recirculation within the reactor vessel is made up of the saturated water from the top of the core or riser flowing to the downcomer and mixing with the colder make-up water. The mixture enters the bottom of the core and heat is added to this coolant fluid over the active core length. The steam generated in the coolant passages creates a natural circulation driving head because of the fluid density differential between the core-riser column and the downcomer leg.

\section{PERFORMANCE ANALYSES}

In the interests of simplicity, natural circulation boiling reactors have been divided into two general categories: those with restrictive-type risers (or chimneys), and those with open, or relatively unrestricted risers. An example of the restrictive type would be a reactor with inactive extensions of the fuel channels of the core. This results in many risers of relatively small hydraulic diameter. An example of the open-type riser would be a reactor having one or more risers of large hydraulic diameter. 
Since the restrictive-type riser offers considerably greater resistance to flow than does the open riser, its associated circulation rates are less. For this reason, the lengths of restrictive-type risers are short, while for the open-type riser the lengths are usually quite long. Another characteristic of the restrictive-type riser is that, since each core channel has its own riser, a reactor can be designed so that a core channel can relieve itself if more power is liberated locally in a channel. The open riser-typedesign has most of its driving head in the riser section which would not be affected by the performance of a single channel. This is essentially the same situation that exists with forced circulation, where parallel channel operation is sometimes a problem.

Performance curves for reactors with restrictive-type and with open-type risers are shown in Figs. 2 to 10 and Figs. 11 to 25 , respectively. The purpose of these curves is primarily to show the interrelationships of various parameters such as power density, geometry, inlet water velocity, steam volume fraction, etc.

In order to eliminate the great number of geometric combinations possible, the hydraulic diameters of the riser and flow channels of Figs. 2 to 10 were assumed to be the same. In Figs. 11 to 25 it was assumed that the hydraulic diameters of the risers were $1 \mathrm{ft}$ and that the total riser flow area was equal to the total core flow area.

There are various bases for comparing boiling reactor performances, but no single one is completely adequate. Comparison of performance in Figs. 2 to 10 is based on a constant value of

$$
\bar{\alpha}_{\mathrm{C}}\left(\rho_{\mathrm{w}}-\rho_{\mathrm{s}}\right),
$$

which is the average density deviation of the core coolant from saturated conditions due to steam volume fraction. This term provides a measure of reactivity tied up by steam in the core and an approximation of the hydrodynamic circulating head for the case of a riserless core. It represents a simple form of comparison rather than a rigorous nuclear, hydrodynamic, or thermodynamic parameter. Three different values of this density deviation term were selected. They represent values that are about $1 / 2,1$, and 2 times that of EBWR at design conditions.

The primary reason for the use of exit steam volume fraction as a basis for comparison in Figs. 11 to 25 is to show a wide range of performance for a given design. The exit steam volume fraction is also a major consideration in evaluating the maximum capacity of a reactor from the standpoint of burnout and stability. For the open riser design it is essentially a direct measure of driving head since practically all of the driving head is due to the steam volume fraction in the long riser. 
Although in Figs. 2 to 10 it appears that the power density increases very markedly with pressure, it should be noted that the increase can be attributed, in part, to the basis of comparison used. However, for a given value of exit steam volume fraction, the power density does increase with pressure (see Figs. 11 to 25 ).

The effect of risers on reactor performance can be evaluated by determining their influence on the coolant flow rate. As the flow rate increases, the ratio of reactor power to steam volume fraction increases, thus improving reactor performance. In restrictive-type riser designs, the greatest benefit is obtained from the first few feet of riser height since the ratio of $\%$ additional driving head to \% additional flow resistance is inherently low. By enlarging the riser diameter, the ratio of $\%$ additional driving head to resistance can be considerably increased.

From Figs. 11 to 25 it is apparent that, although some of the core channels are restrictive, circulating water velocities are quite high and exit qualities and steam volume fractions are low with these open riser designs.

In calculating the performance curves shown in Figs. 2 to 25 , the following assumptions were made: (1) uniform axial thermal flux; (2) steam volume fraction in the riser was the same as that at the core exit; and (3) the external circulation flow resistance was negligible $(H=2)$. An example of the effect of external resistance on a particular arrangement is shown in Fig. 26.

No study has been made of the possibility of burnout or instability; therefore, some of the operating conditions shown may be unattainable.

\section{GENERAL DESIGN CONSIDERATIONS}

\section{A. Pressure}

One of the most interesting features of this study is the manner in which pressure affects performance. Power density increases at higher pressures and circulating rates do not inherently drop off with pressure. The basic reasons for this are threefold:

(1) On the constant density deviation basis, driving head does not drop off with pressure.

(2) Although the two-phase friction factor multiplier does increase with increasing steam volume fraction, this is more than offset by the decrease in friction due to pressure increase.

(3) At very high pressure there is additional driving head due to the density-temperature relationship of water. At the high power densities of high pressure operation, this additional head can be quite significant. 


\section{$1 /$}

Figure 27 shows a comparison between the average density deviation term, $\bar{\alpha}_{\mathrm{C}}\left(\rho_{\mathrm{w}}-\rho_{\mathrm{s}}\right)$, and the trus core coolant density deviation, $\left(\rho_{\mathrm{w}}-\bar{\rho}_{\mathrm{C}}\right)$, for a given arrangement. The terms are the same at lower pressure, but differ considerably at higher pressure because of the effect of the inlet subcooled water density.

An interesting performance characteristic of higher pressure operation is shown in Figs. 23 to 25. As power density is increased, the true core coolant density, $\bar{\rho}_{\mathrm{C}}$, increases. Such interrelationships of power density, coolant density, and inlet subcooling suggest a reactor with low core steam volume fraction operating by natural circulation near the critical pressure, possibly with temperature control.

At higher pressures the boiling lengths inherently become shorter (about $35 \%$ of core length at 2500 psi for uniform axial flux distribution); therefore lower steam volume fractions and qualities will exist in the zone of higher heat flux. This shorter boiling length and its location near the discharge end should be beneficial from the standpoints of burnout and stability.

The possible beneficial aspects of high pressure operation have to be weighed against associated drawbacks. Burnout considerations presently appear to dictate a general lowering of permissible heat fluxes above system pressures of about 1000 psi. Maximum reactor vessel diameters at high pressures further lower attainable total power output. Such additional questions as those concerning water dissociation at high power densities and pressures, and the resultant effects on turbines, piping, fossil-fired superheating, etc., have yet to be answered.

For high pressure reactor operation it is more probable that stainless cladding of the fuel elements will be required. Depending upon the particular design, this may significantly affect neutron economy. Further nuclear considerations, such as the requirement of a greater amount of reactivity tied up in core coolant density changes between operating tem. perature and room temperature, must also be evaluated.

\section{B. Geometry}

As one would expect, smaller channels result in lower recirculation velocities. However, for given power densities, larger channels result in higher heat fluxes. It is difficult to evaluate the true significance of channel size since so little is understood about natural circulation quality burnout.

The proper selection of a riser is probably the most important single aspect of natural circulation boiling reactor design. The optimum riser 
design will probably incorporate desirable features of both basic riser types. Information is not available to completely evaluate the effect of a change in geometry between the core and riser. Air-water experiments at atmospheric pressure(7) have shown that the vapor fraction $(\alpha)$ increases with a reduction of flow area and decreases with an increase of flow area. The magnitude of these changes is not great and is a function of the area ratios. It is expected that the changes will be less at the higher pressures. When information is available along these lines, truly optimum designs of risers and more thorough studies will be possible.

Because the open riser has such a high ratio of driving head to resistance, the limitations of height are most likely to be determined primarily by economic or other considerations connected with its size.

\section{Burnout}

In order to evaluate the potential of boiling water reactors, it is necessary to know where and how burnout occurs. This is probably the greatest basic uncertainty in boiling reactor design. No correlations of net boiling burnout are known that adequately describe its relationship with pressure, velocity, quality, steam volume fraction, and geometry. As previously mentioned, present data indicate a general lowering of burnout heat flux in going above $1000 \mathrm{psi}$, and, since there are promising aspects of natural circulation performance at higher pressures, the question of burnout heat flux becomes more important. Since burnout may be significantly increased by higher velocity, as well as by lower quality and steam volume fraction, the open riser-type reactor design looks particularly promising.

Very high pressure burnout bears further study. The properties of steam and water at pressures slightly less than the critical pressure are such that a sudden phase change in this region may not lead to a burnout or excessive temperature condition due to channel blockage as can happen at lower pressure.

\section{Stability}

It is the writers' belief that the boiling reactor stability problem is primarily one of hydrodynamics, with nuclear aspects being secondary. A trend of increased stability with pressure has been shown by reactor and thermal-hydrodynamic experiments up to 600 psi. Experiments have shown that restrictions in natural circulation operation or the use of a pump (at the same flow rate) are other means of aiding stability.

Reactor stability should improve at higher pressures - one reason being the inherent shorter boiling length. It is also expected that 
13

higher circulation flow rates, along with lower steam volume fraction, will be beneficial. However, the effect of water height above the core, with or without risers, on stability is not well known and requires further study.

\section{E. Efficiency}

The effect of steam pressure and temperature on Rankine cycle efficiency is shown in Fig. 28. Although efficiency generally increases with pressure without superheat, higher pressure steam becomes quite moist upon expansion. Thus moisture separation and/or extraction becomes more important if superheat is not used. At higher pressures, nuclear superheat appears promising, since there is no extreme density reduction in the transition from the liquid to the vapor phase. Nuclear superheat designs in the form of a light water, two-pass arrangement or with a separate superheating core, appear worth investigating. Some nuclear superheat is possible even at lower pressures for certain heavy water designs.

Feed-water preheat may also be desirable. Turbine extraction can be used to heat make-up water as well as to lower turbine moisture content. However, the resulting increase in cycle efficiency must be balanced against the decreased core coolant density resulting from the warmer makeup water. The effect of make-up temperature on reactor performance is shown in Fig. 29 for a particular arrangement.

Many variations of systems with superheat, preheat, reheat, etc., are possible. This is, of course, a major study by itself. Particularly interesting variations with reheat or other types of heat exchange in the top of the downcomer may prove worthwhile for certain designs.

\section{CONCLUSIONS}

The potential of natural circulation reactors appears very good and less limited than has generally been believed. Since the "art" of boiling reactor design is considerably more complex and less established than that of pressurized water reactors, and since a number of factors that contribute toward optimum design require more investigation, the true capabilities of natural circulation boiling reactors are not completely known at present. However, some specific conclusions that can be drawn are:

1. Forced circulation is not always necessary to achieve high flow rates. Natural circulation velocities can be greater than flow rates normally associated with forced circulation design.

2. High pressures offer promise of high power density operation. 


$$
14
$$

3. Power density is likely to be a primary limiting feature of low pressure design, while burnout heat flux is likely to be the primary limiting consideration of higher pressure design.

4. There is considerable need for further analytical and experimental development of significant parameters and correlations. Information about the mechanism of burnout, the effect of high open-riser geometry, and the predictions of hydrodynamic-nuclear stability is particularly needed. In general, studies in the higher pressure and higher velocity ranges are greatly needed. 
15

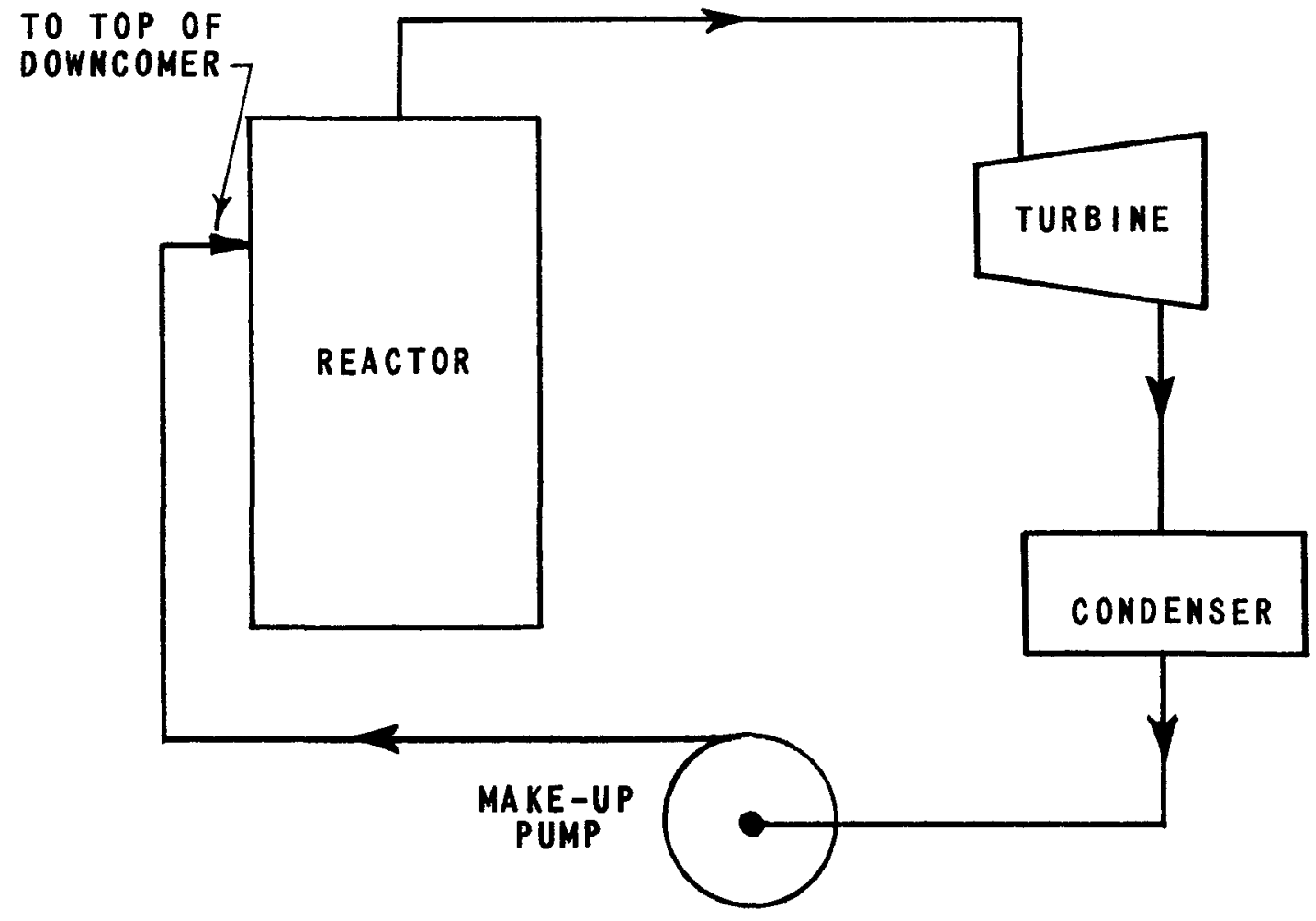

FIG. I

BASIC SYSTEM 


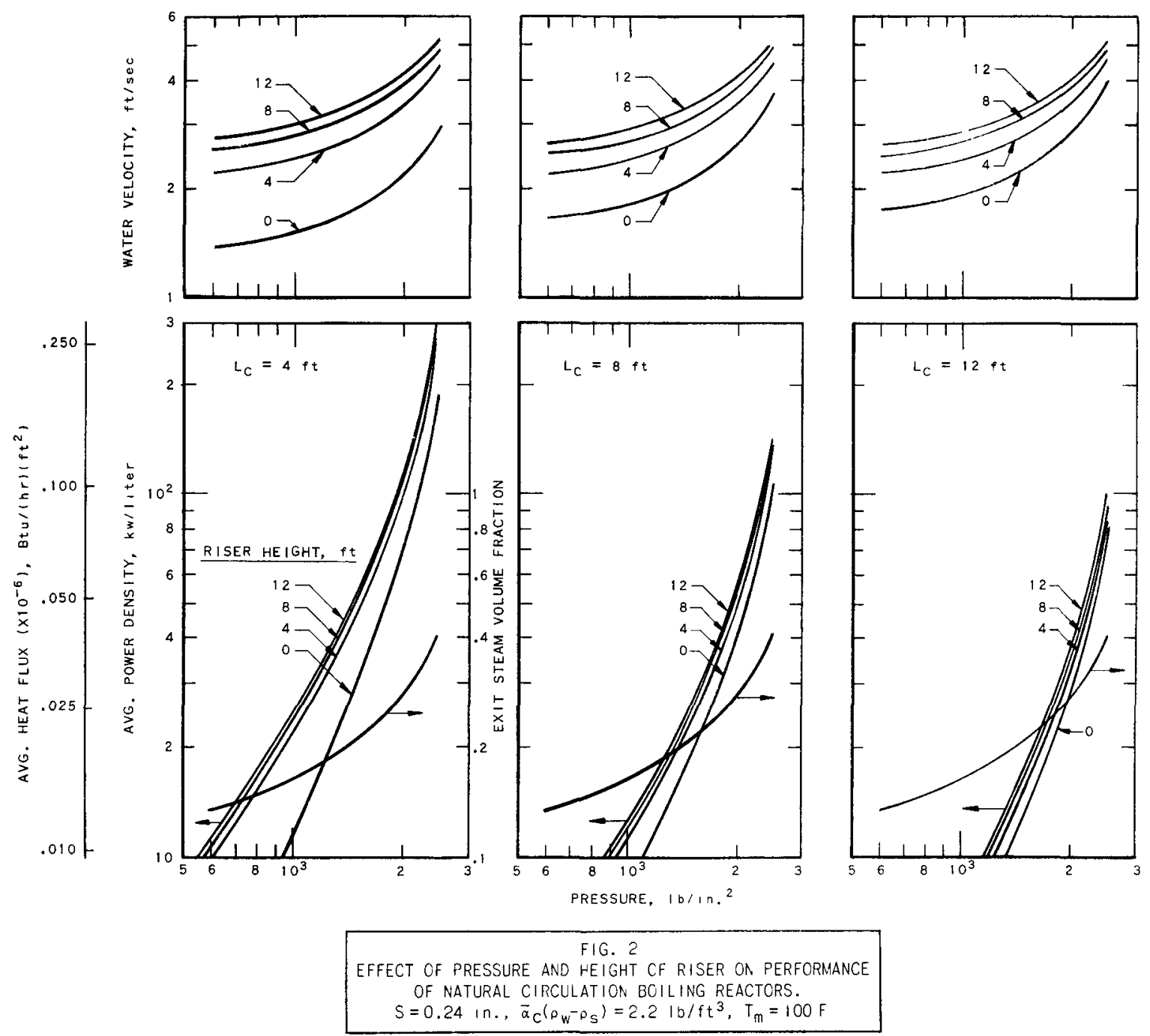




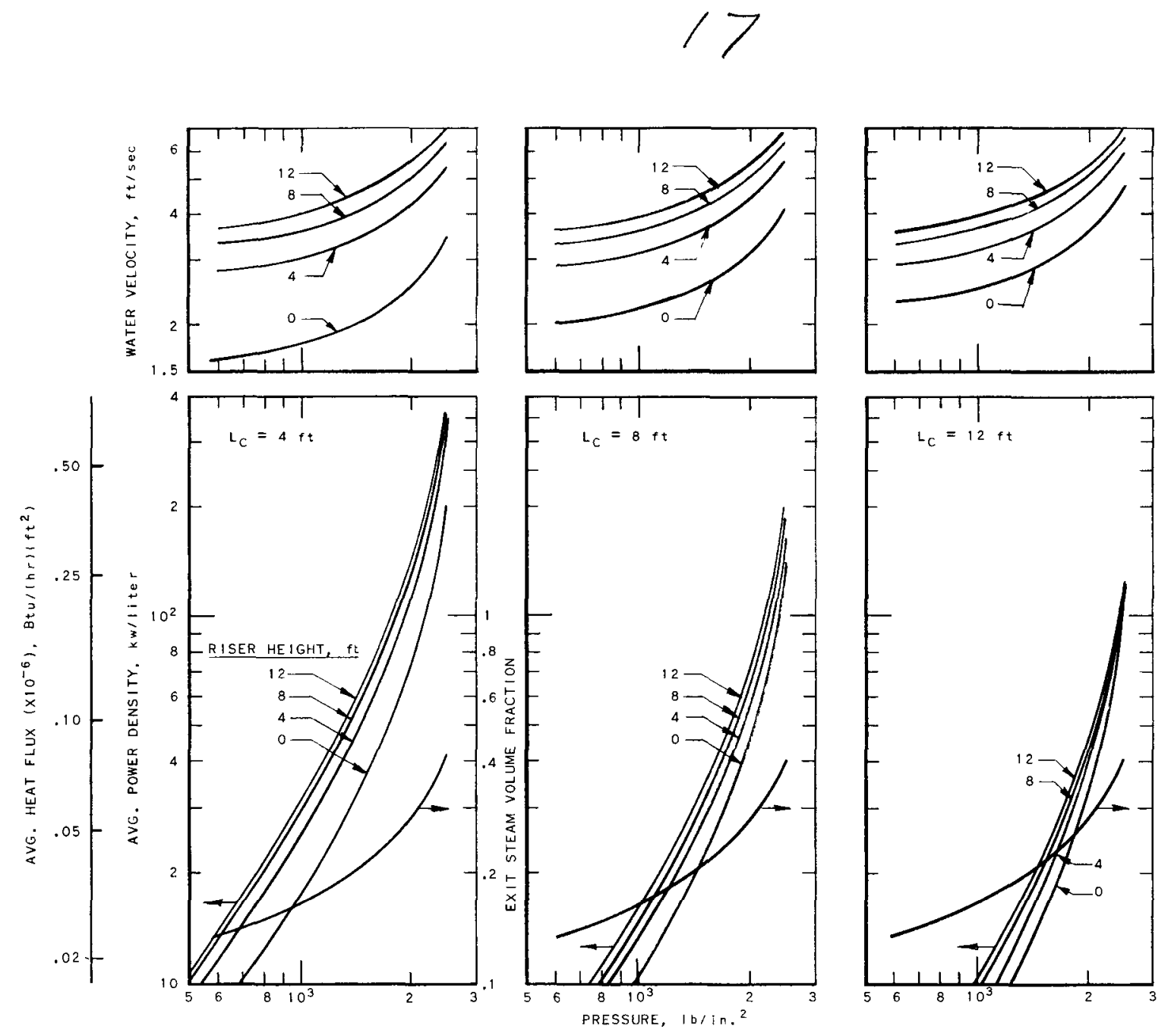

FIG. 3

EFFECT OF PRESSURE AND HEIGHT OF RISER ON PERFORMANCE OF NATURAL CIRCULATION BOILING REACTORS.

$S=0.48 \mathrm{in} . ; \bar{\alpha}_{C}\left(\rho_{w_{m}}-\rho_{S}\right)=2.2 \mathrm{lb} / \mathrm{ft}^{3} ; T_{m}=100 \mathrm{~F}$ 
18

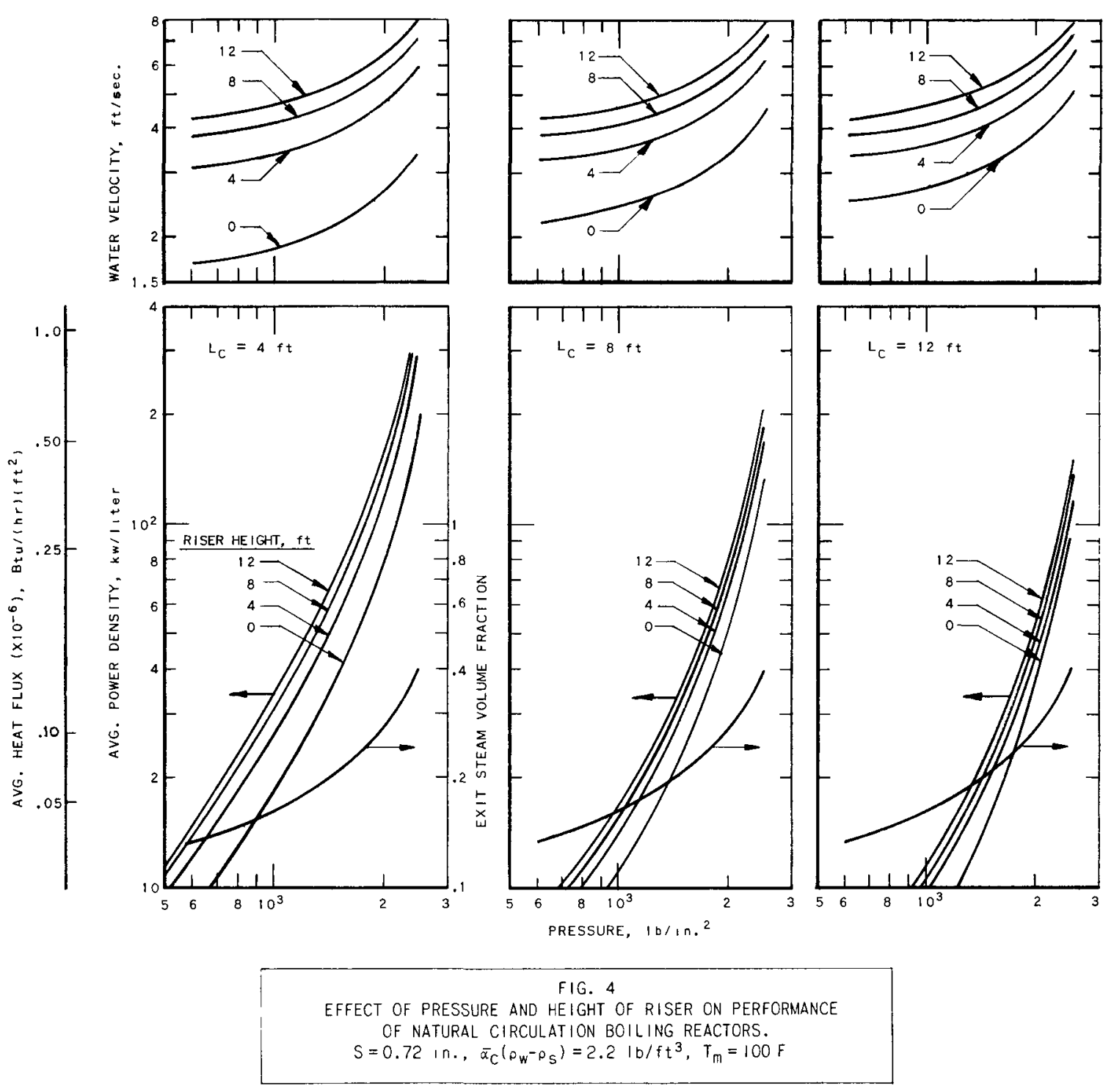




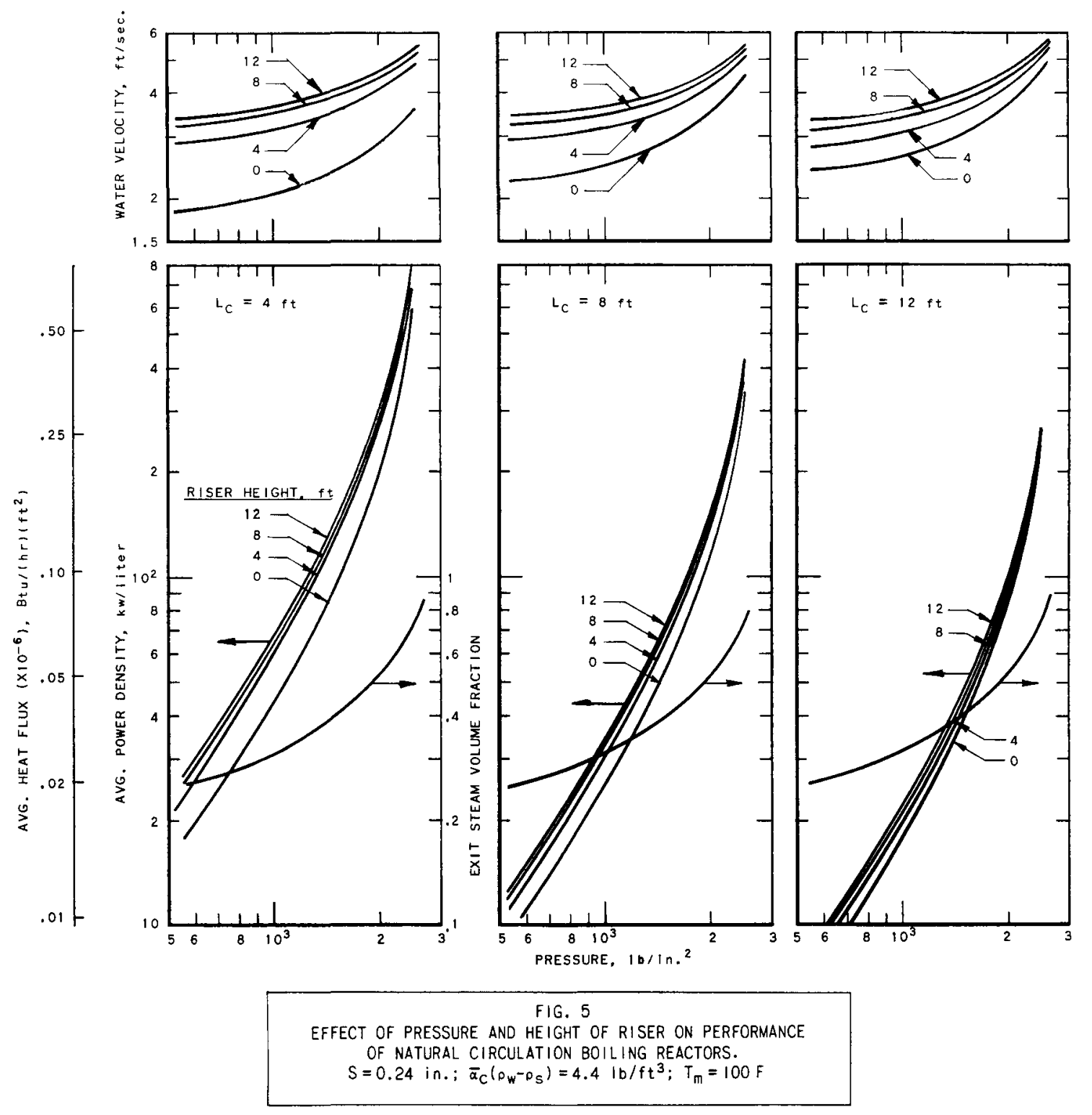


50

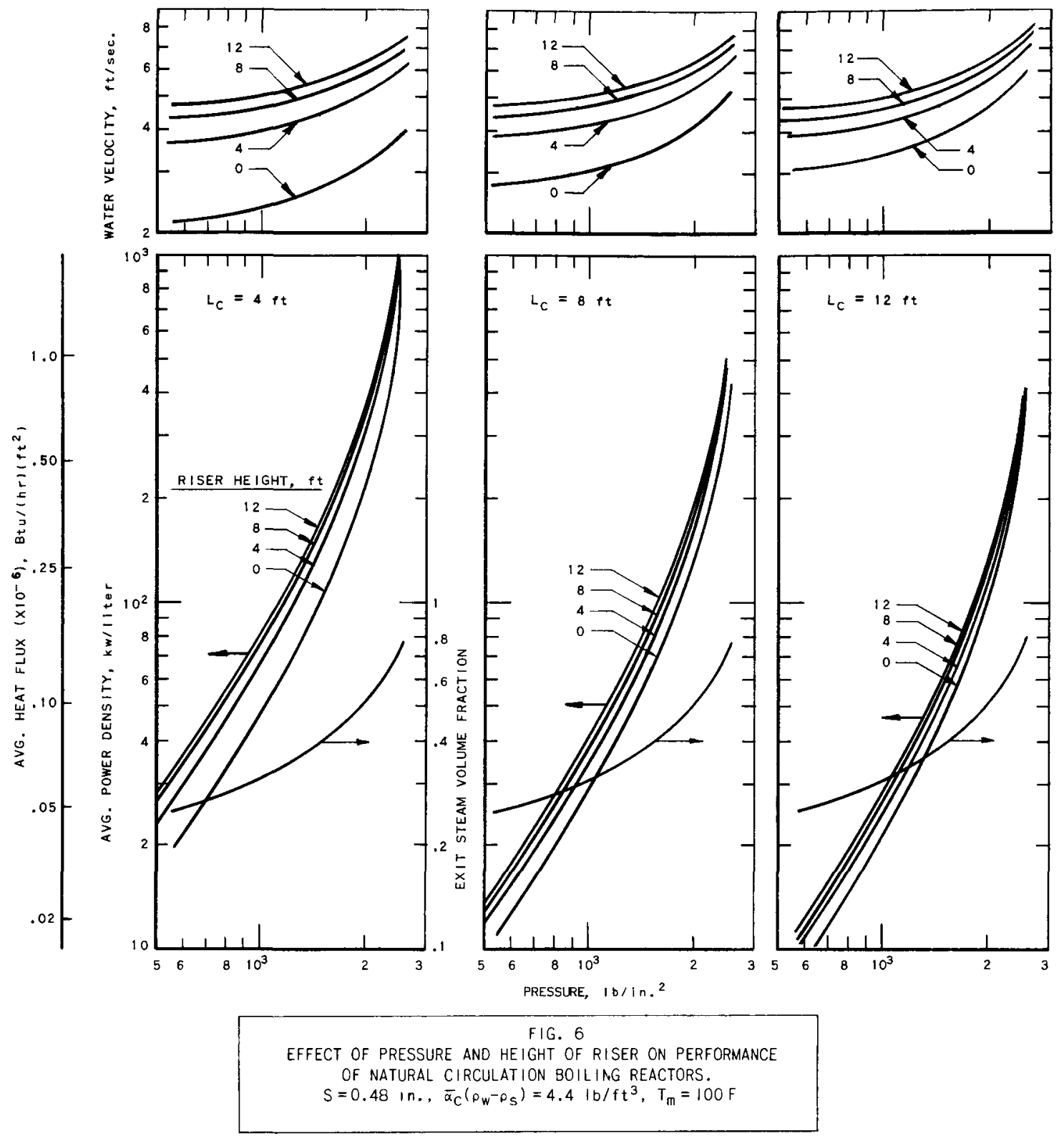


21

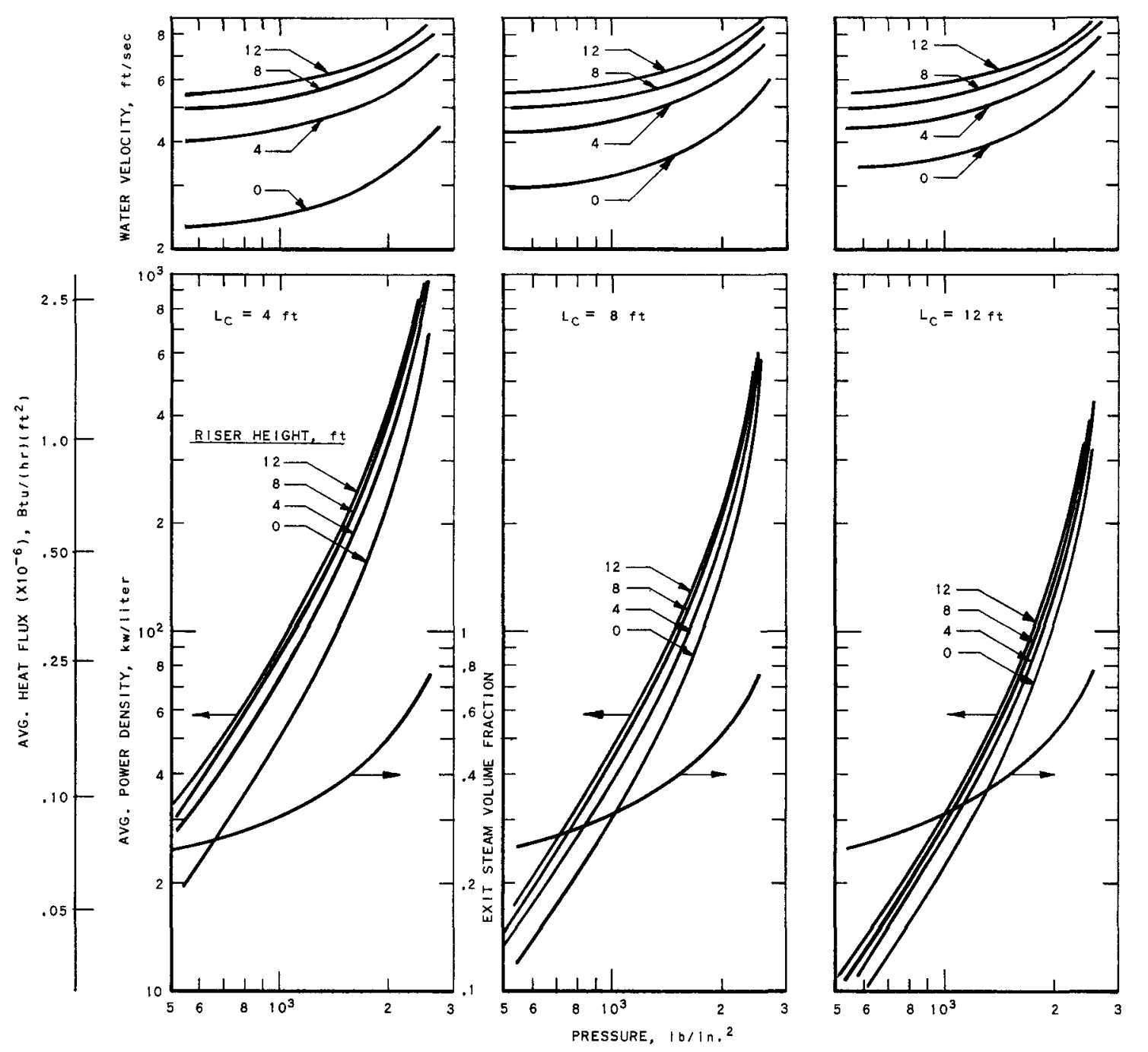

FIG. 7

EFFECT OF PRESSURE AND HEIGHT OF RISER ON PERFORMANCE

OF NATURAL CIRCULATION BOILING REACTORS.

$S=0.72 \mathrm{in} . ; \bar{a}_{C}\left(\rho_{w}-\rho_{S}\right)=4.4 \mathrm{lb} / \mathrm{ft}^{3} ; T_{m}=100 \mathrm{~F}$ 
22

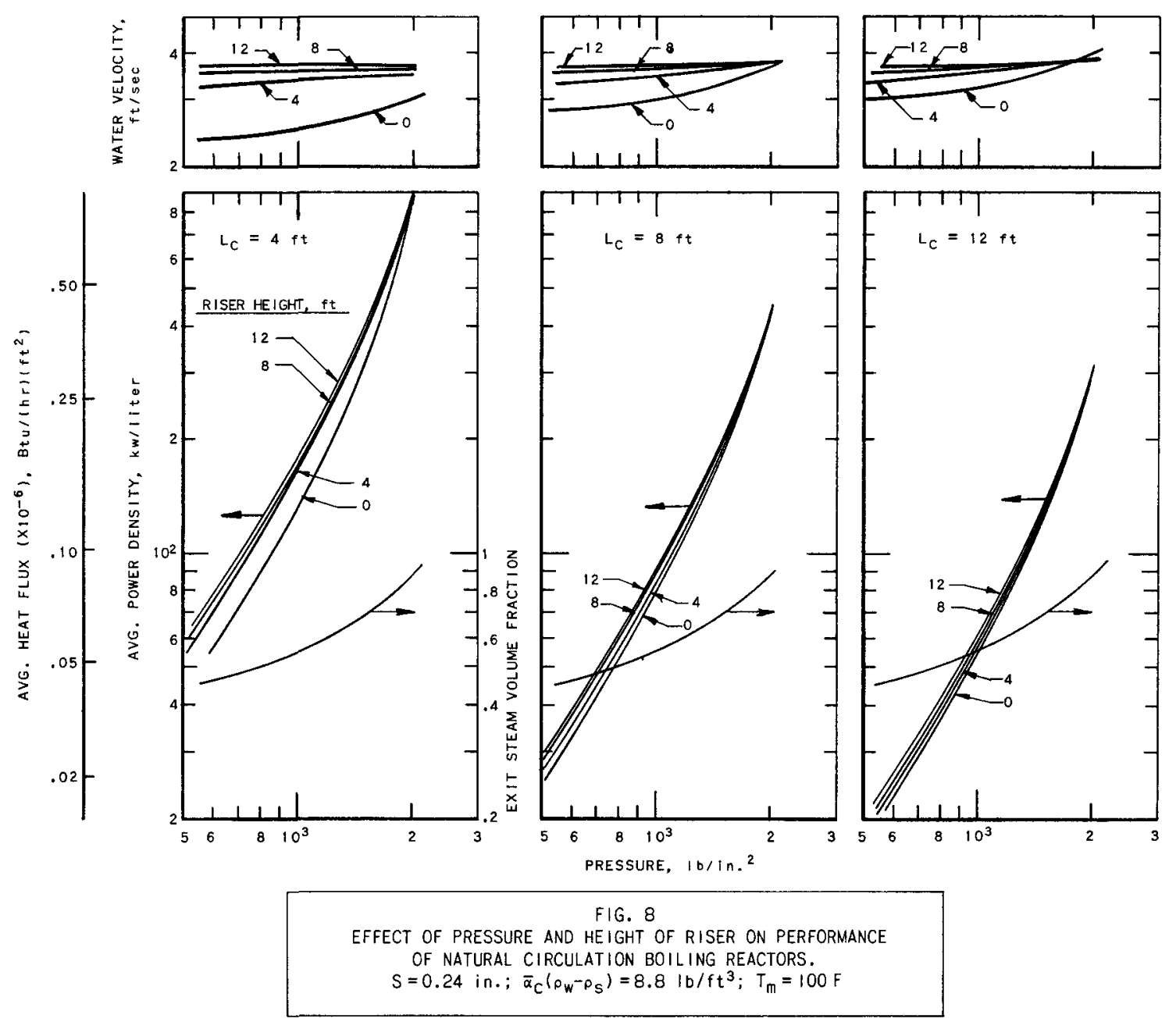


$-3$

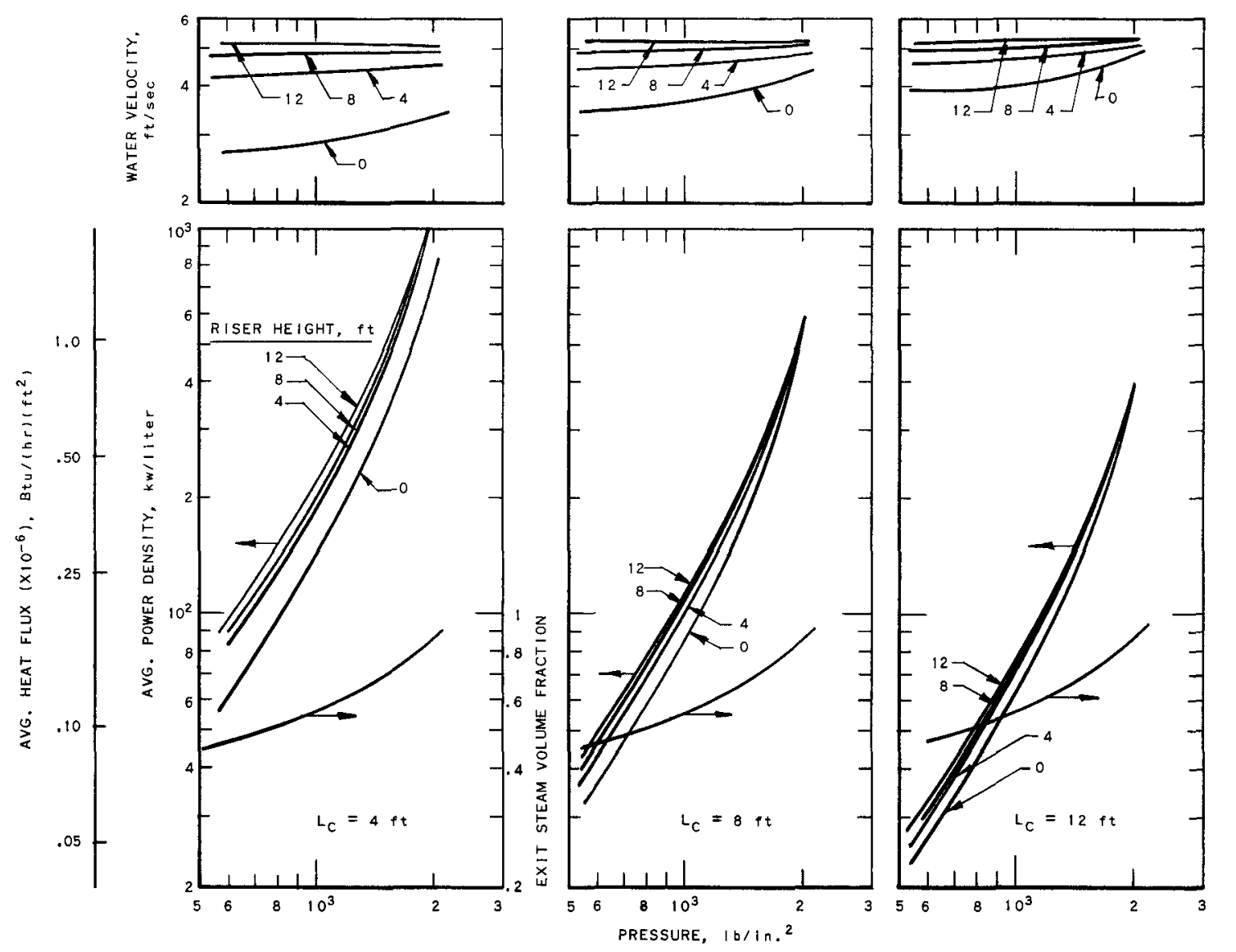

FIG. 9

EFFECT OF PRESSURE AND HEIGHT OF RISER ON PERFORMANCE

OF NATURAL CIRCULATION BOILING REACTORS.

$S=0.48 \mathrm{in} . ; \bar{\alpha}_{C}\left(\rho_{W}{ }^{-0} s\right)=8.8 \mathrm{ib} / \mathrm{ft}^{3} ; T_{m}=100 \mathrm{~F}$ 


\section{4}

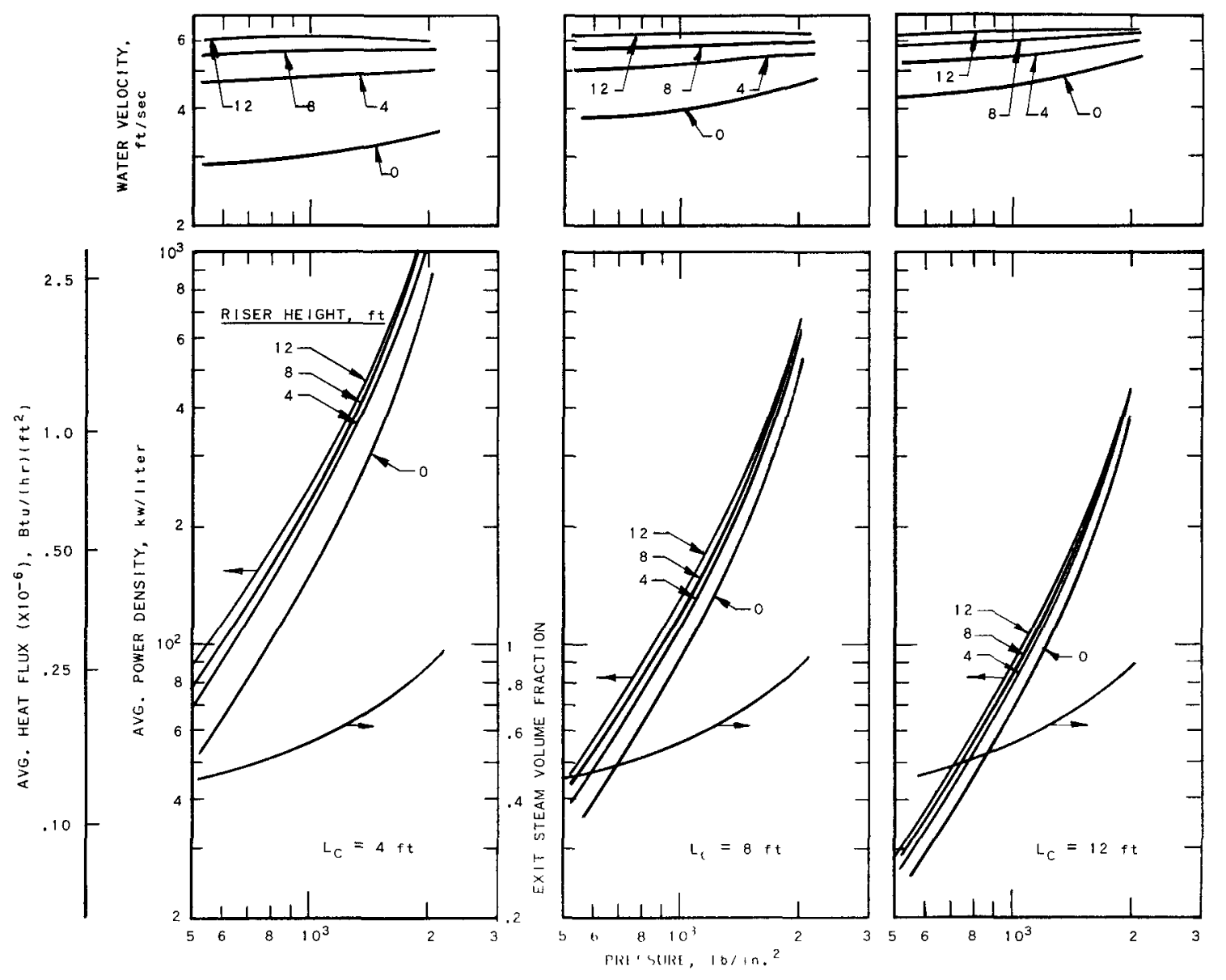

FIG. 10

EFFECT OF PRESSURE AND HEIGHT OF RISER ON PERFORMANCE OF NATURAL CIRCULATION BOILING REACTORS.

$S=0.72 \mathrm{~lm}, \bar{\alpha}_{C}\left(\rho_{\mathrm{W}}-\rho_{\mathrm{S}}\right)=8.8 \mathrm{lb} / \mathrm{ft}^{3}, \mathrm{~T}_{\mathrm{m}}=100 \mathrm{~F}$ 
25
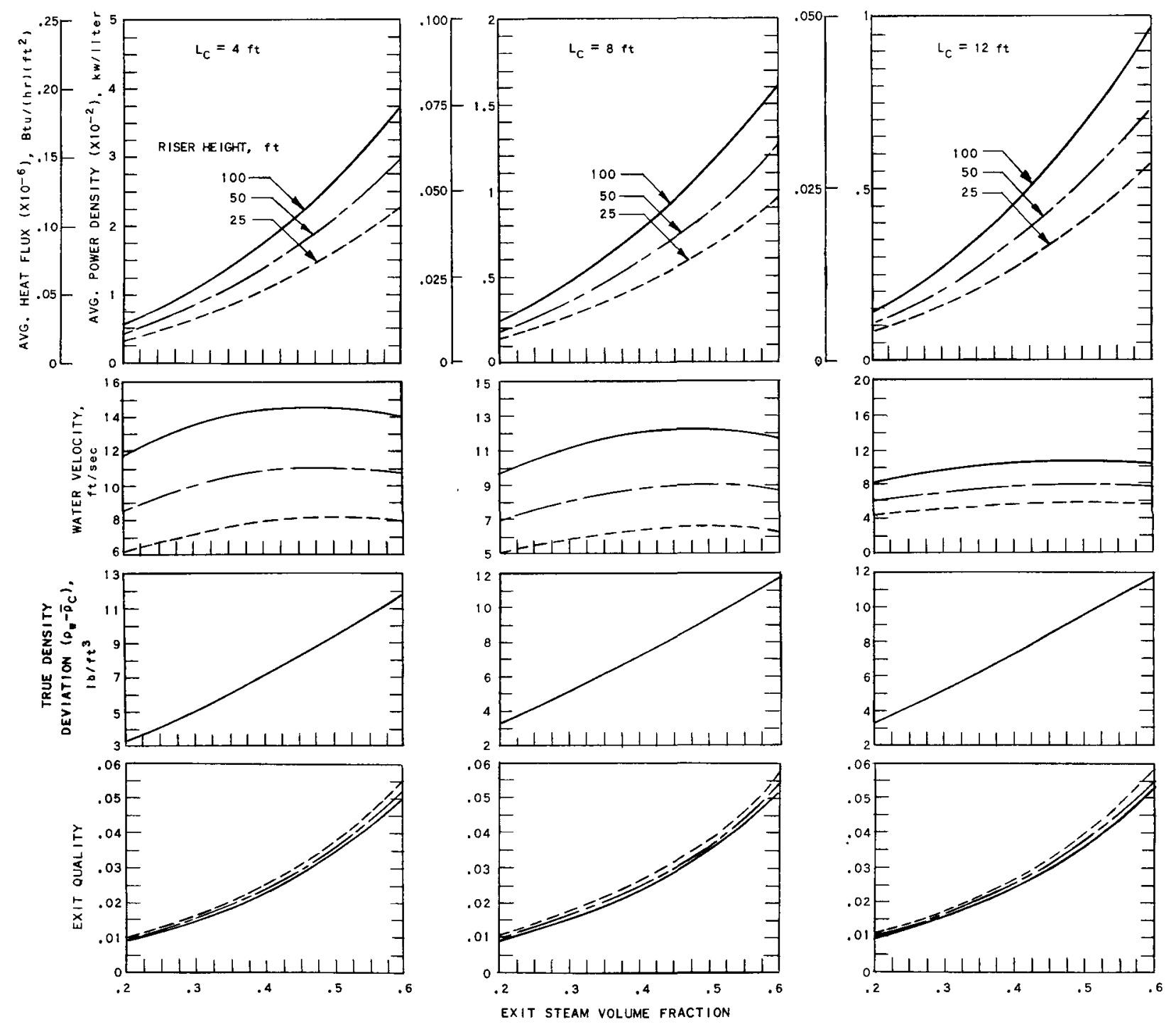

FIG. II

EFFECT OF RISER HEIGHT AND EXIT STEAM VOLUME FRACTION ON PERFORMANCE OF NATURAL CIRCULATION BOILING REACTORS $S=0.12 \mathrm{in.;} P=600 \mathrm{lb} / \mathrm{in}^{2}$ 
96
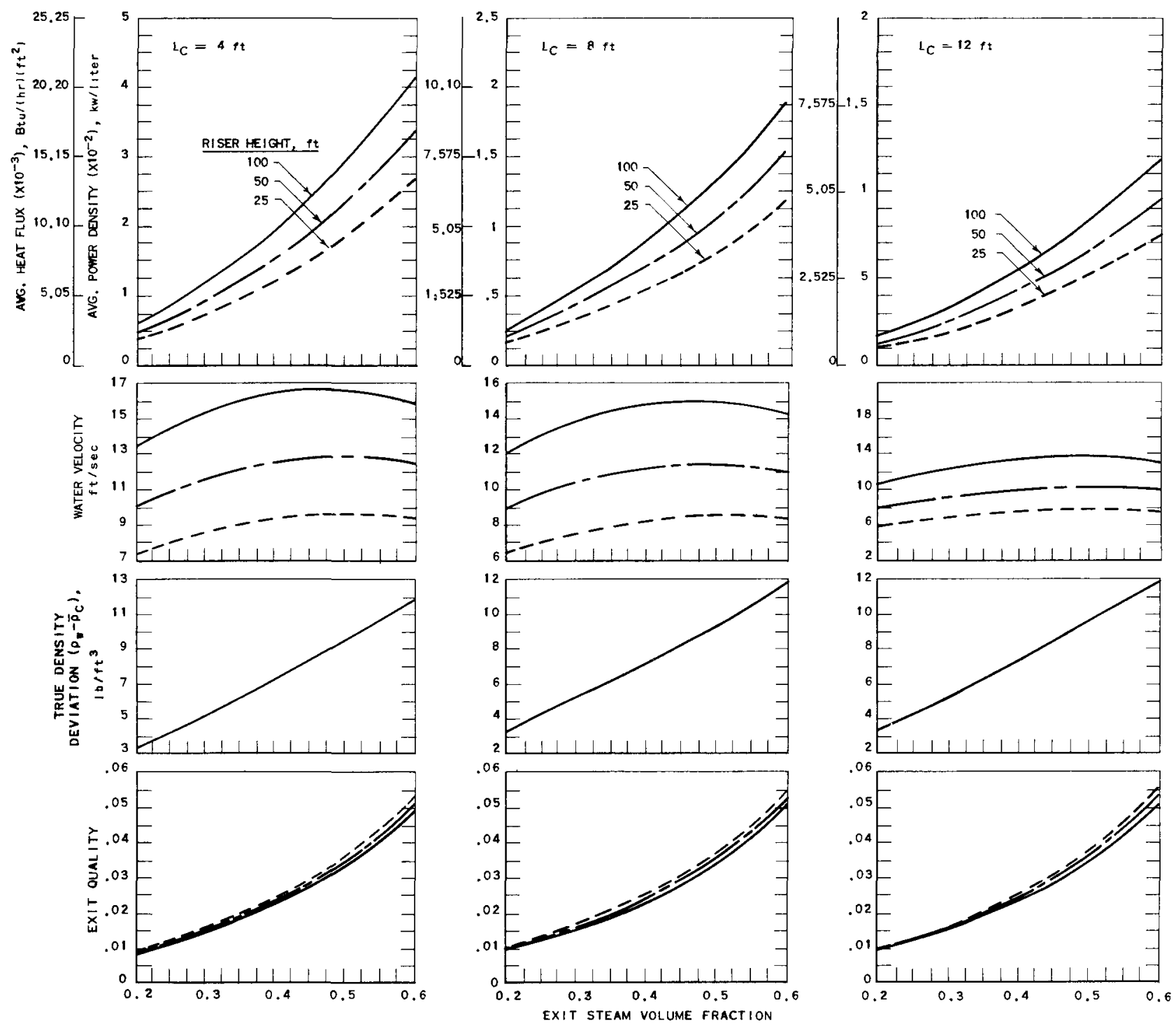

FIG. 12

EFFECT OF RISER HEIGHT AND EXIT STEAM VOLUME FRACTION

ON PERFORMANCE OF NATURAL CIRCULATION BOILING REACTORS. $S=0.25 \mathrm{in} ., P=600 \mathrm{lb} / \mathrm{in} .{ }^{2}$ 

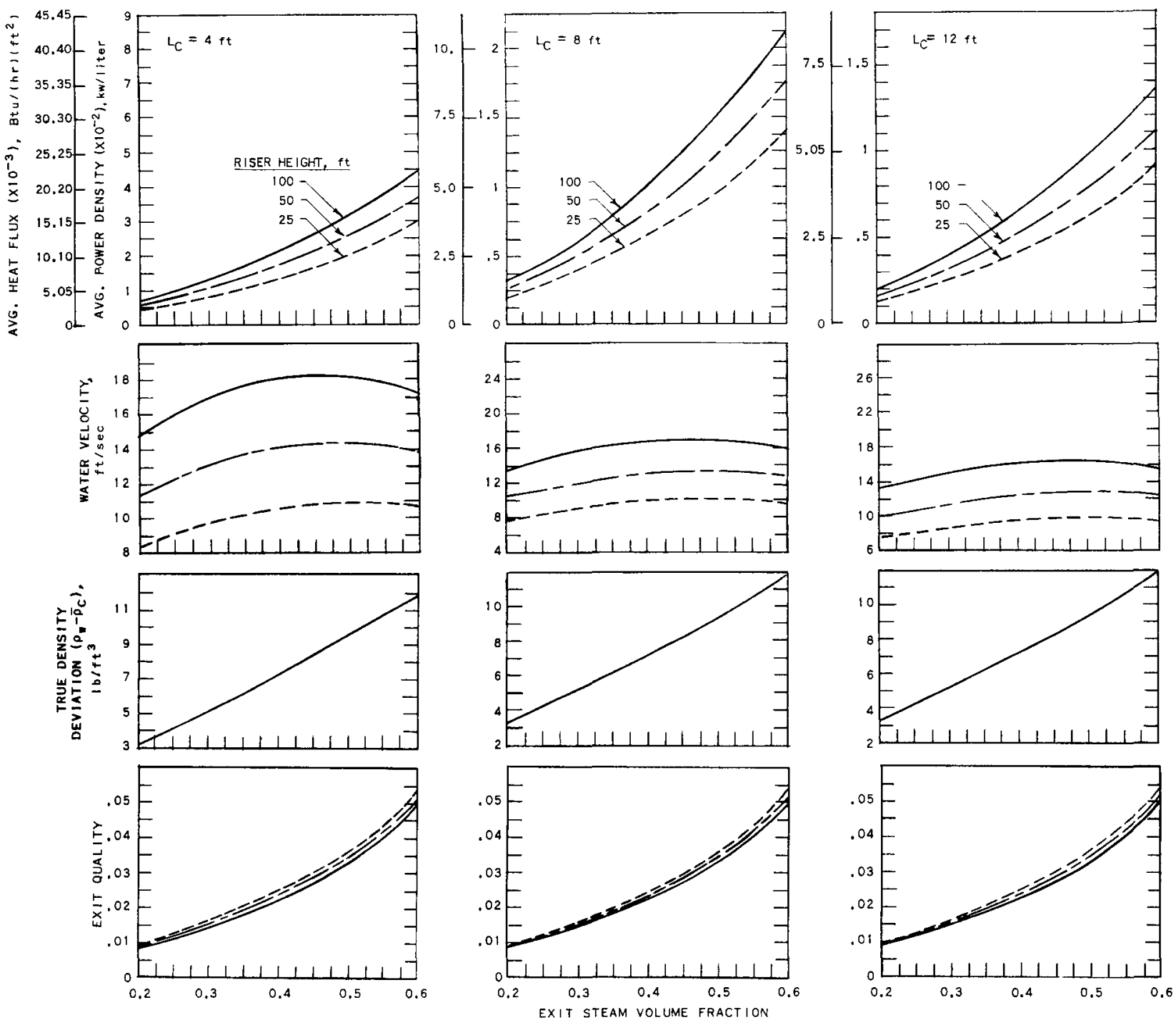

FIG. 13

EFFECT OF RISER HEIGHT AND EXIT STEAM VOLUME FRACTION ON PERFORMANCE OF NATURAL CIRCULATION BCILING REACTORS $S=0.5 \mathrm{in.} . \mathrm{P}=600 \mathrm{ib} / \mathrm{in}^{2}$ 
28
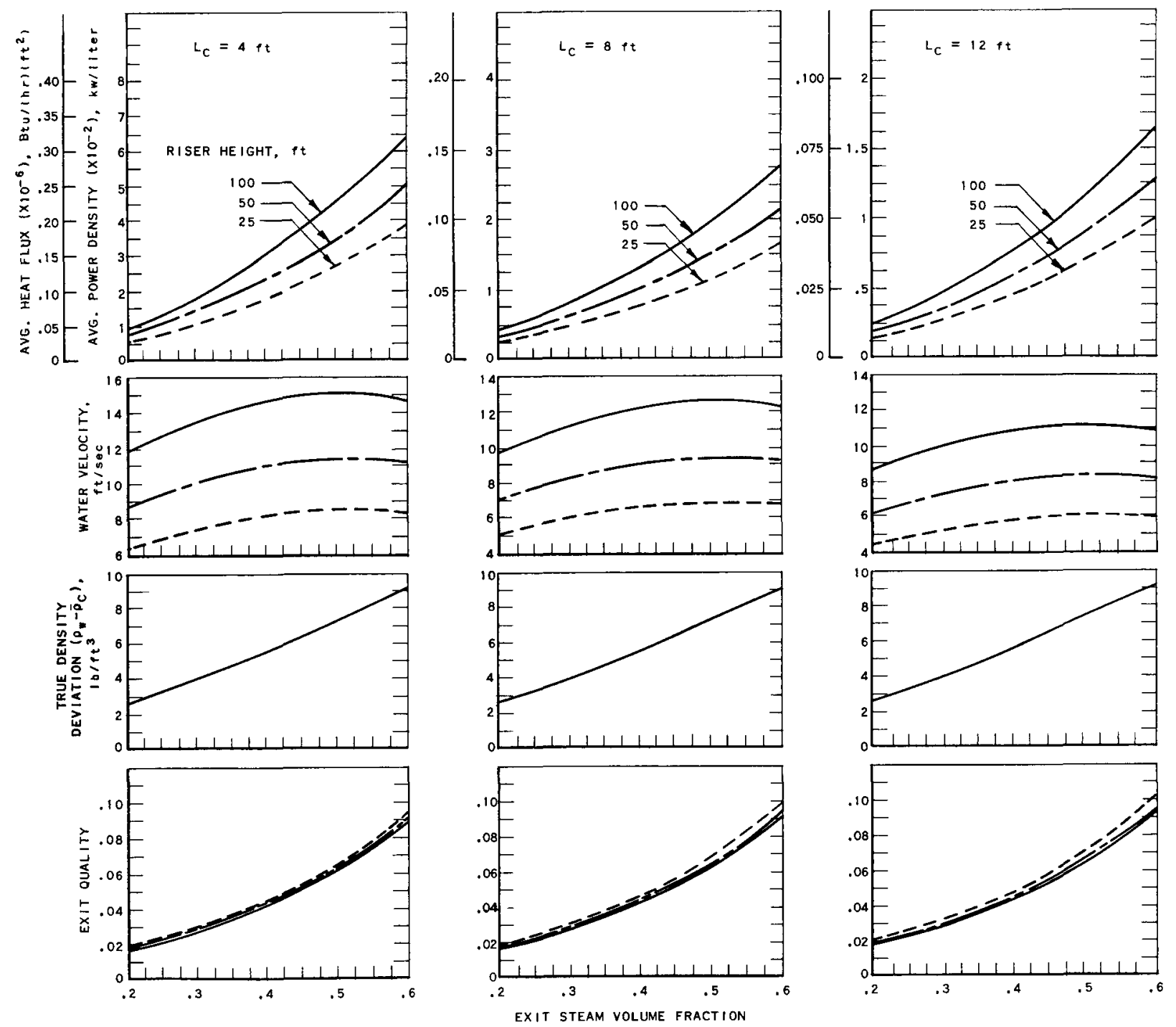

FIG. 14

EFFECT OF RISER HEIGHT AND EXIT STEAM VOLUME FRACTION ON PERFORMANCE OF NATURAL CIRCULATION BOILING REACTORS $S=0.12 \mathrm{ln} . ; P=1000 \mathrm{lb} / \mathrm{ln}^{2}$ 
29
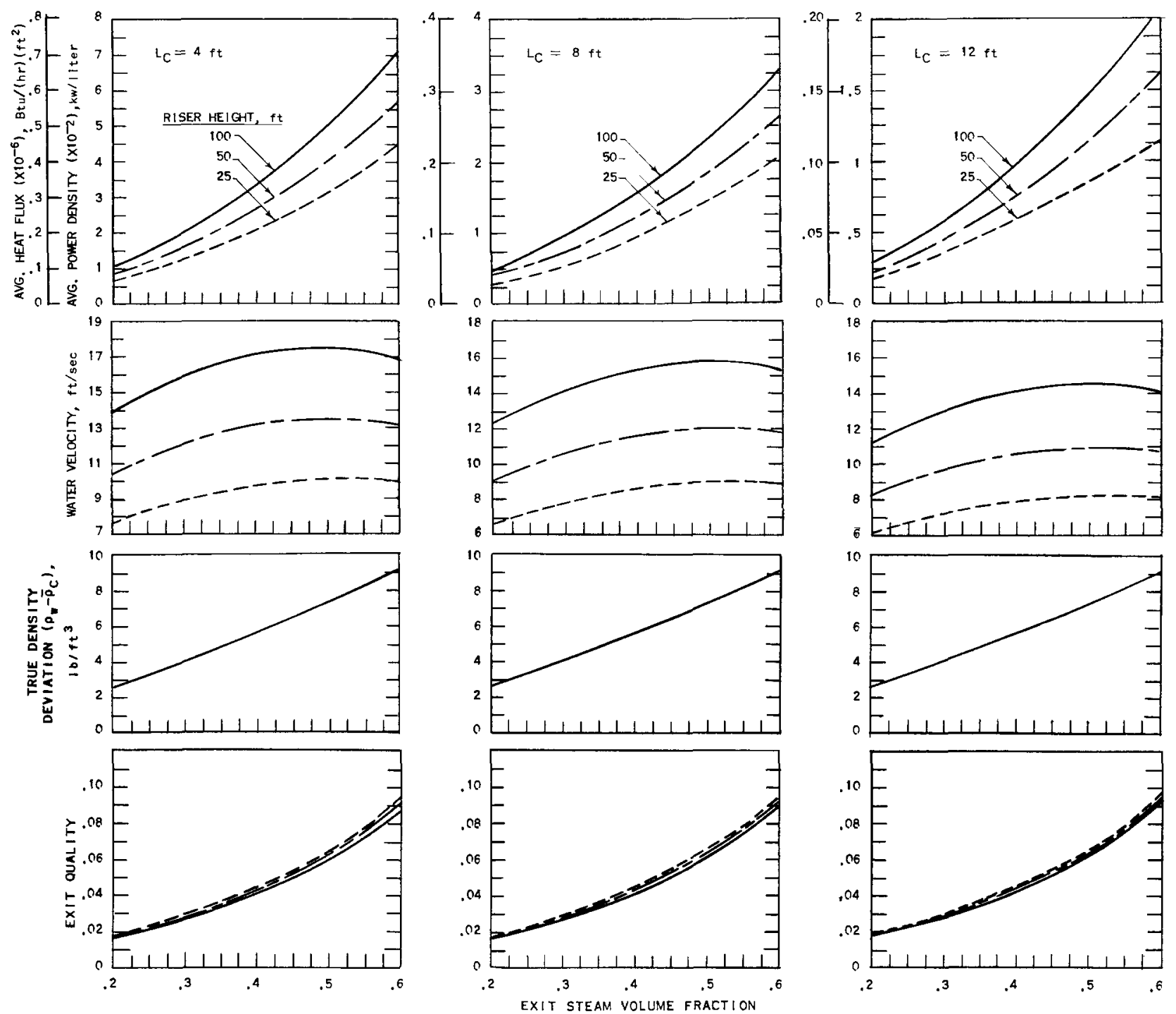

FIG. 15

EFFECT OF RISER HEIGHT AND EXIT STEAM VOLUME FRACTION ON PERFORMANCE OF NATURAL CIRCULATION BOILING REACTORS. $S=0.25 \mathrm{in} ., P=1000 \mathrm{ib} / \mathrm{in.}^{2}$ 
30
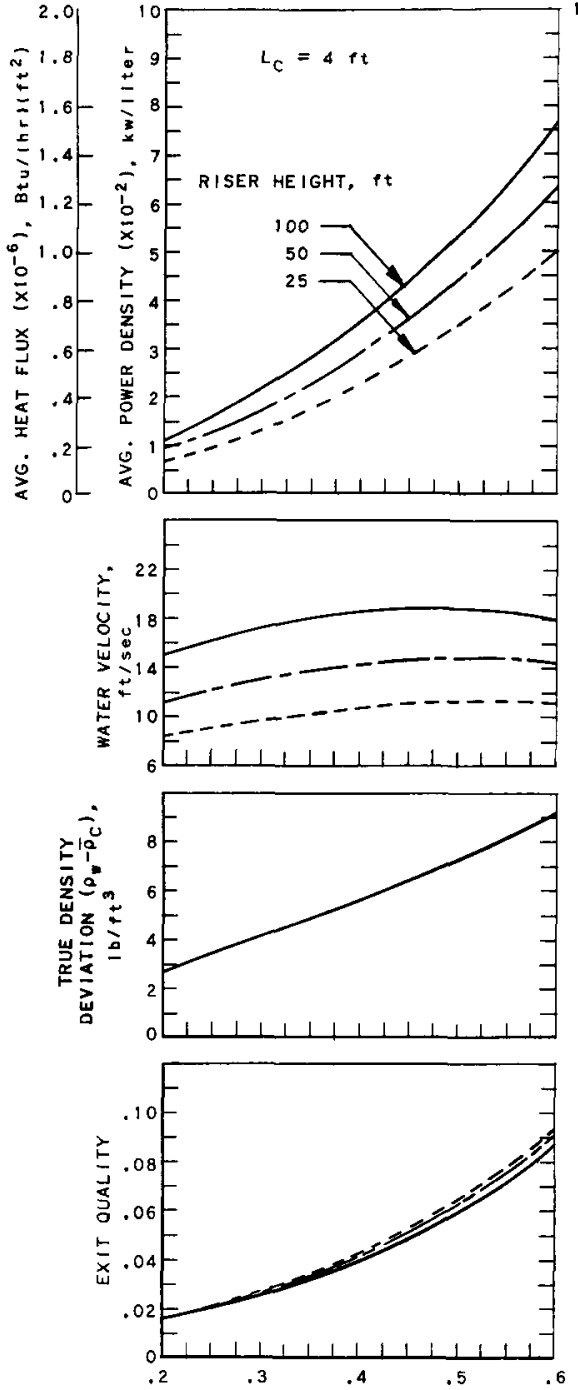
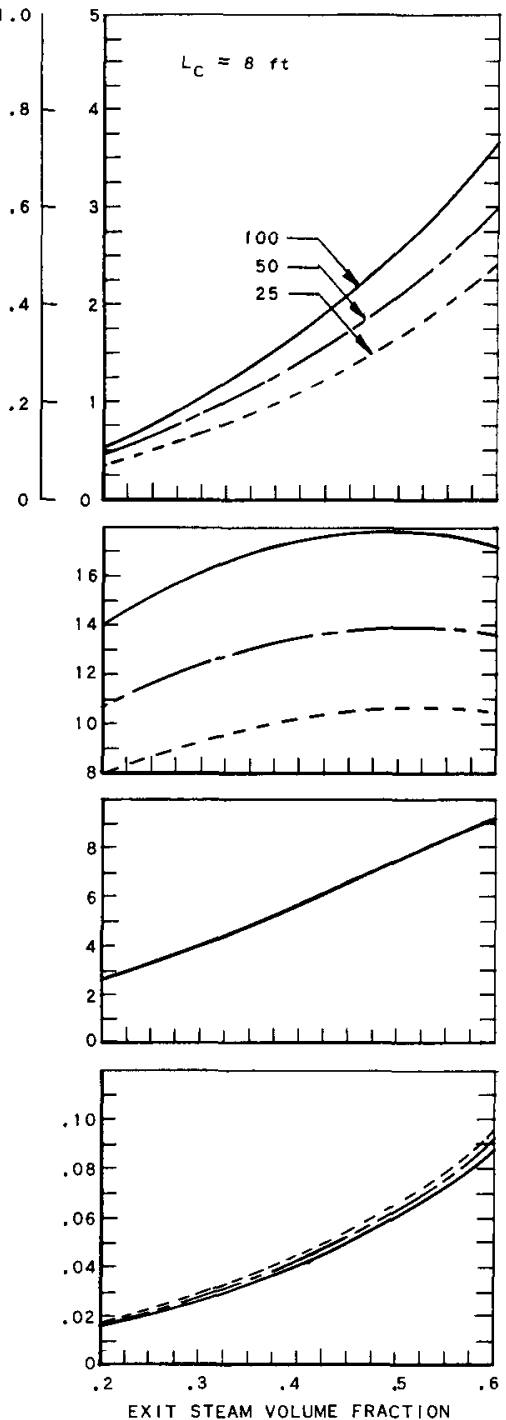
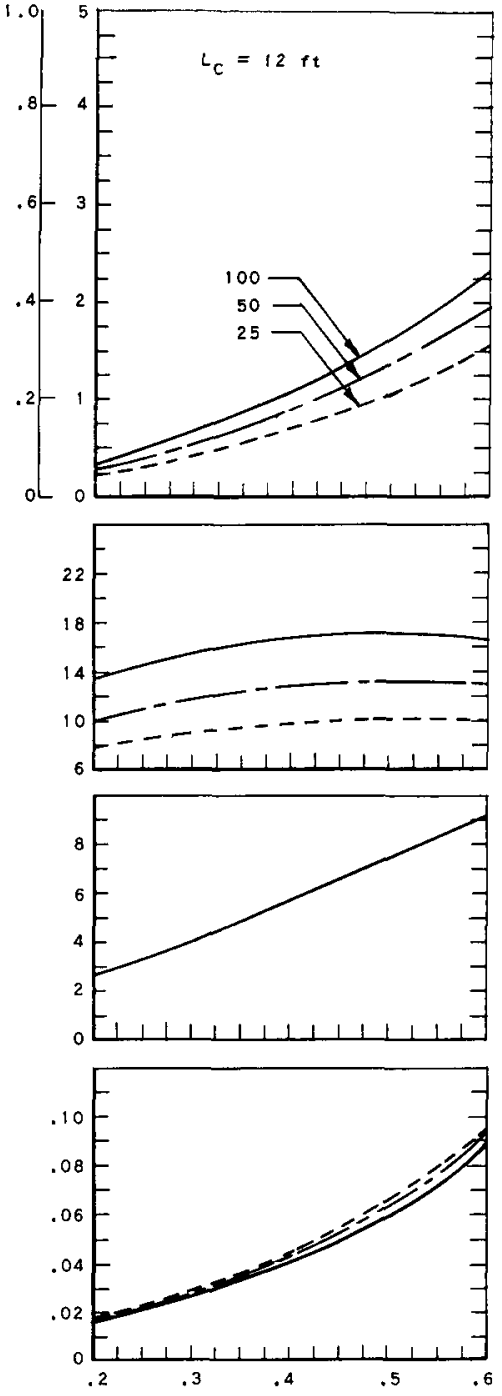

FIG. 16

EFFECT OF RISER HEIGHT AND EXIT STEAM VOLUME FRACTION ON PERFORMANCE OF NATURAL CIRCULATION BOILING REACTORS.

$$
S=0.5 \mathrm{in} . ; \quad P=1000 \mathrm{lb} / \mathrm{in.}^{2}
$$


31
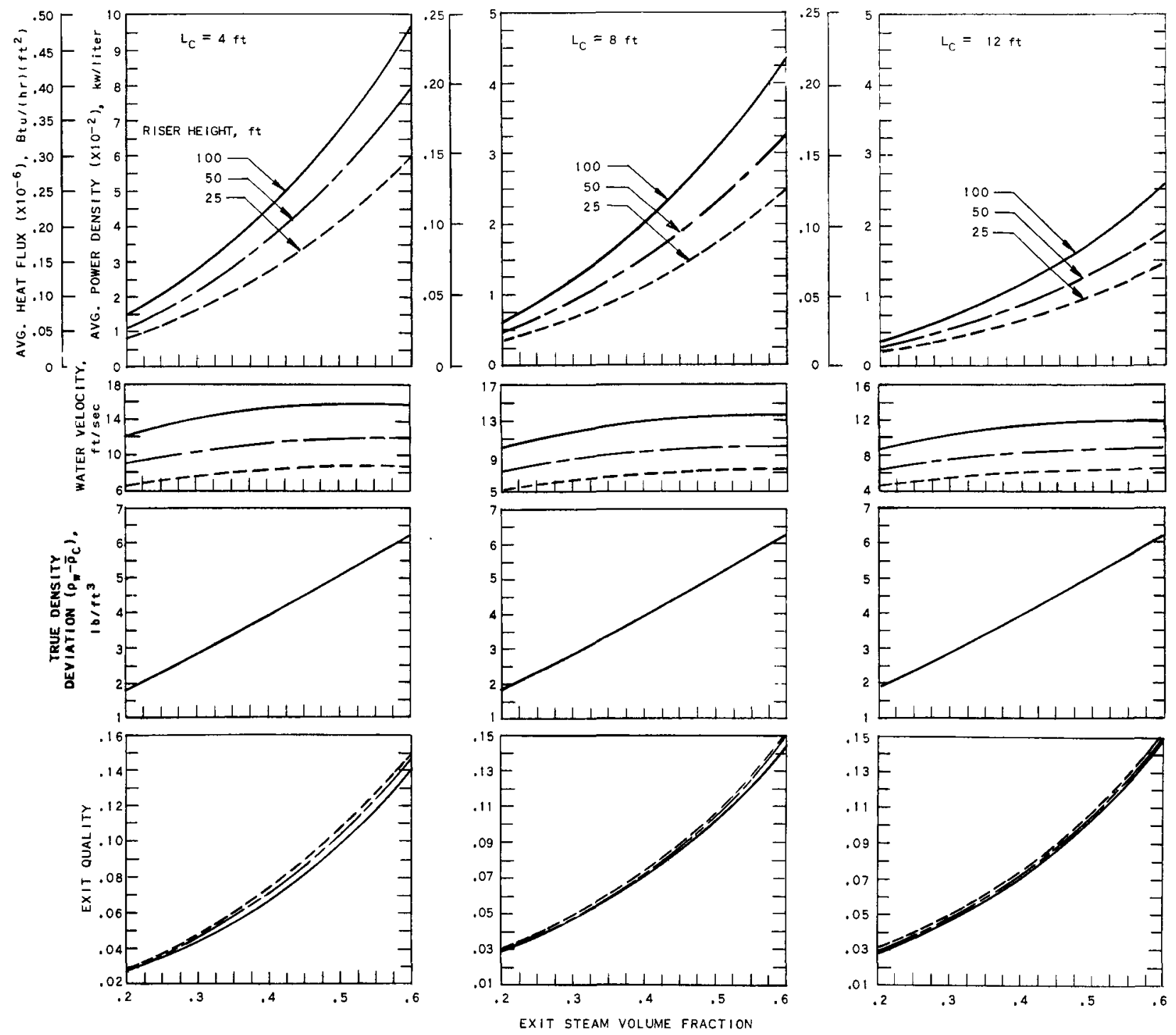

FIG. I7

EFFECT OF RISER HEIGHT AND EXIT STEAM VOLUME FRACTION ON PERFORMANCE OF NATURAL CIRCULATION BOILING REACTORS $S=0.12 \mathrm{in.;} P=1500 \mathrm{lo} / \mathrm{in}^{2}$ 
32
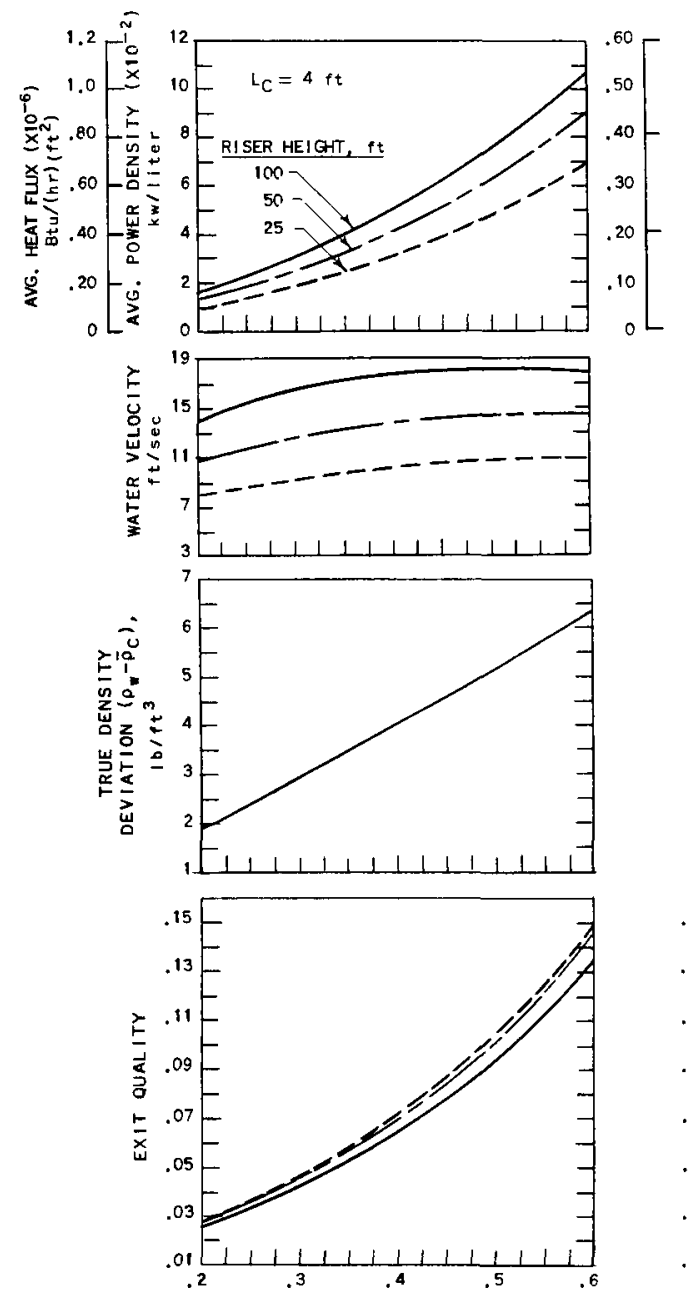
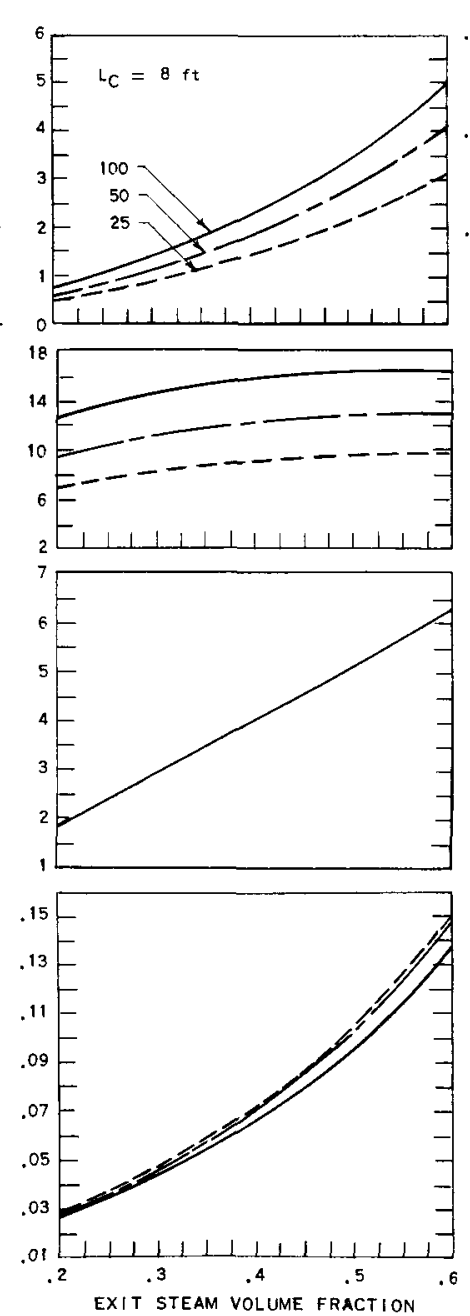
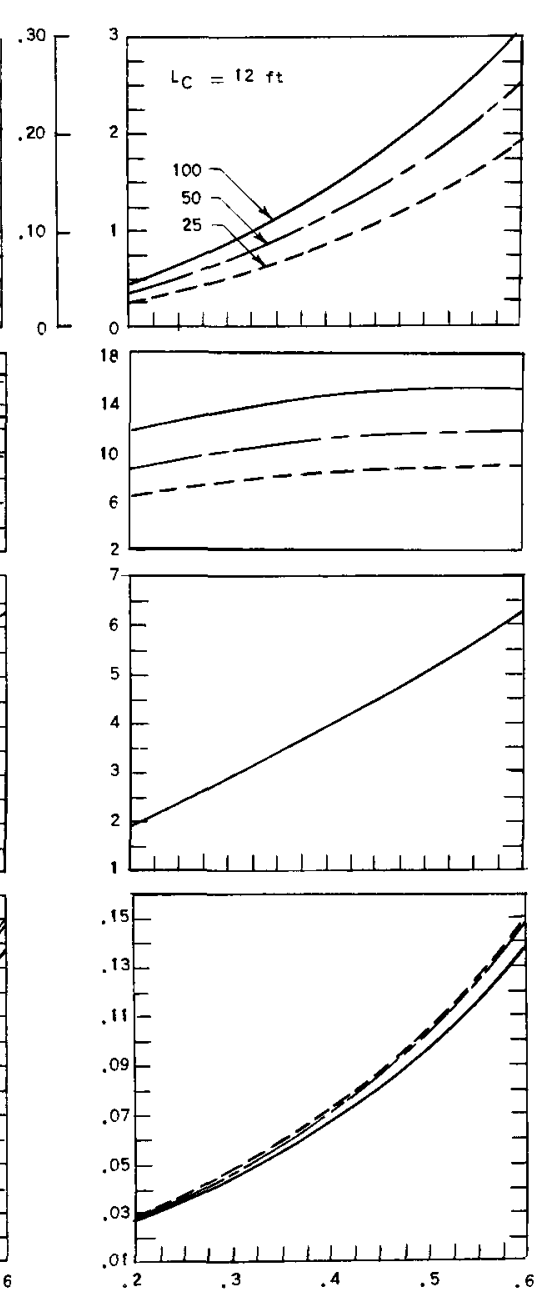

FIG. 18

EFFECT OF RISER HEIGHT AND EXIT STEAM VOLUME FRACTION ON PERFORMANCE OF NATURAL CIRCULATION BOILING REACTORS $\mathrm{S}=0.25 \mathrm{in} ., P=1500 \mathrm{lb} / \mathrm{in}^{2}$ 
33
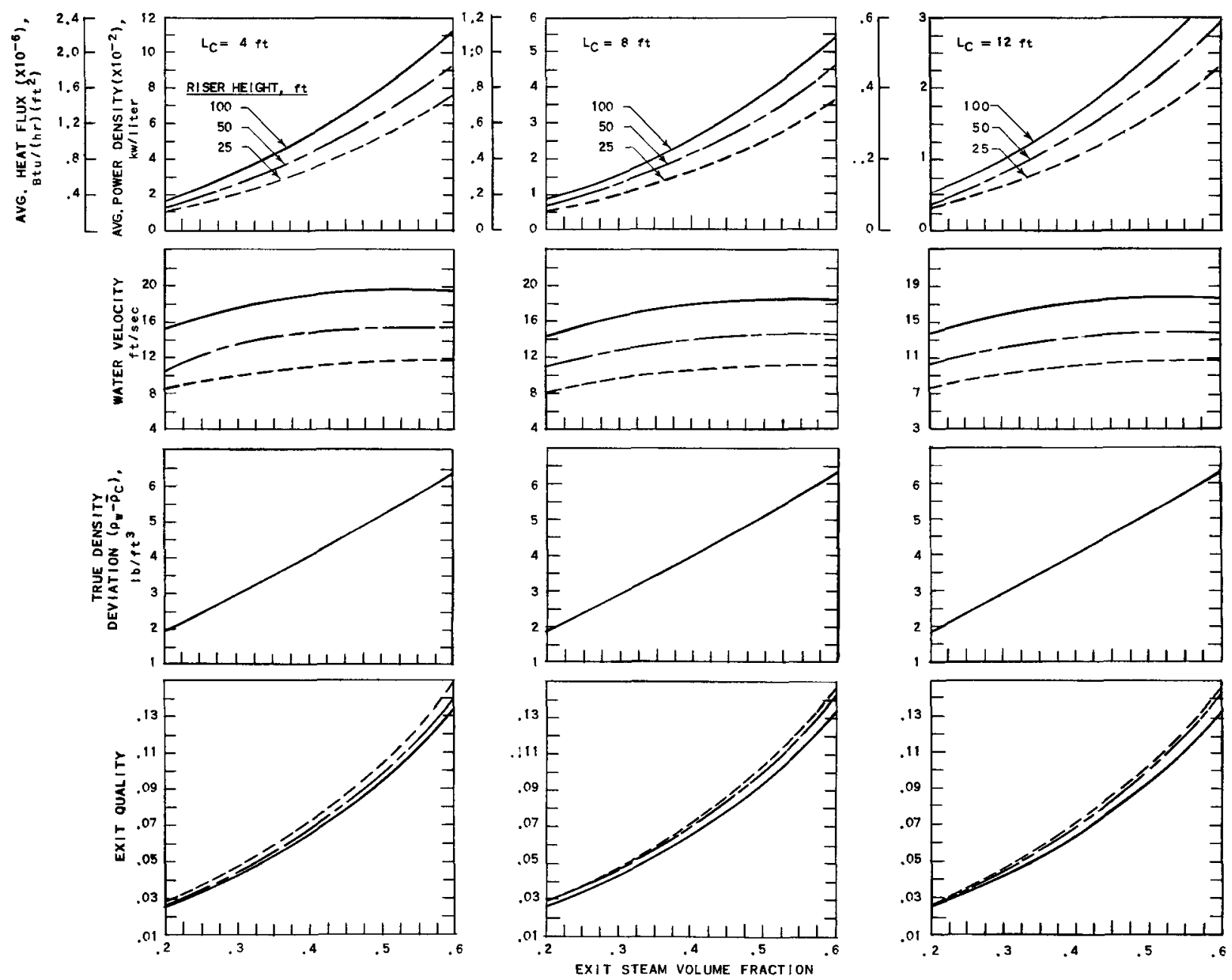

F1G. 19

EFFECT OF RISER HEIGHT AND EXIT STEAM VOLUME FRACTION ON PERFORMANCE OF NATURAL CIRCULATION BOILING REACTORS. $S=0.5$ in.; $P=1500 \mathrm{lb} / \mathrm{in}^{2}$ 
34
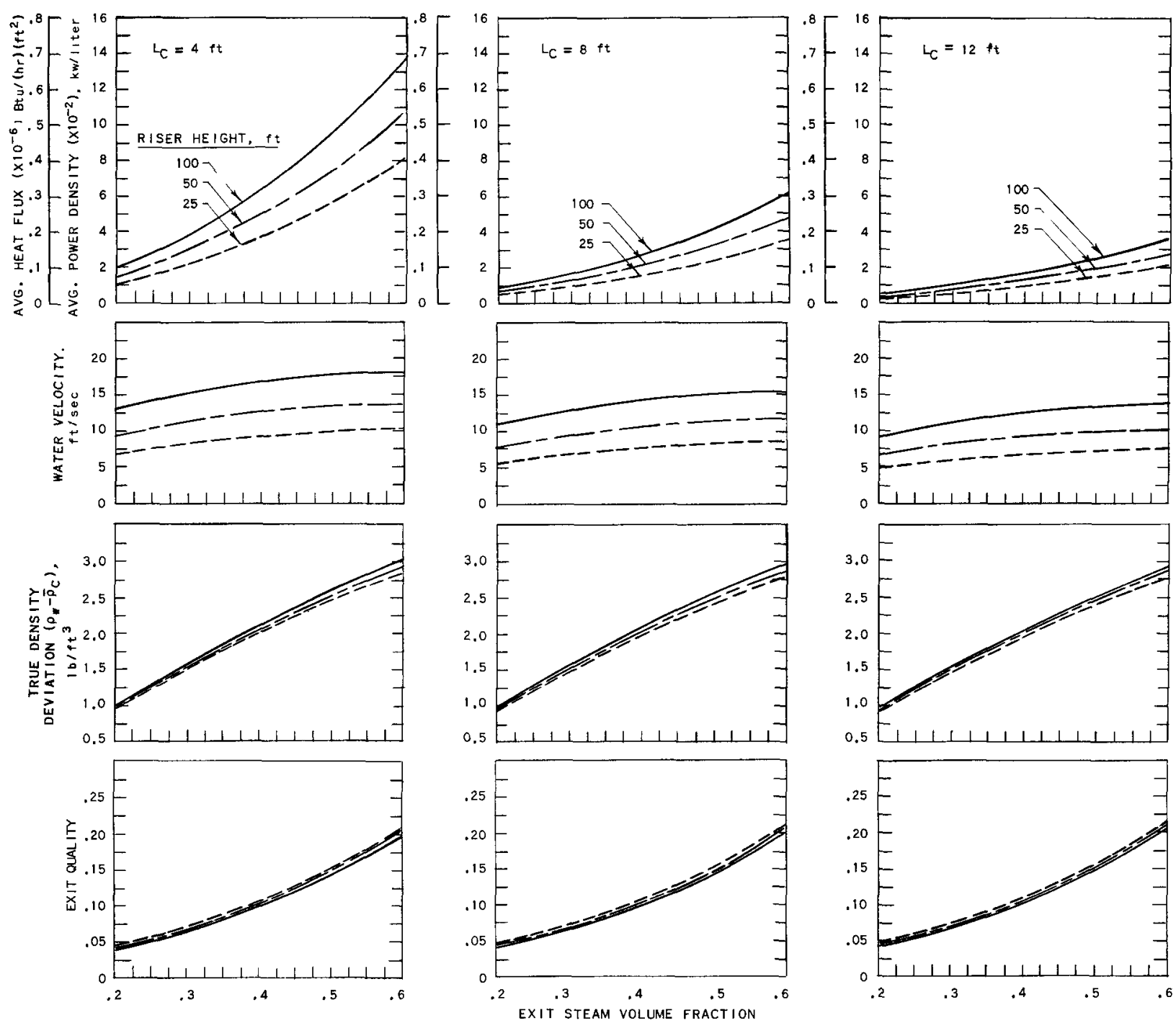

FIG. 20

EFFECT OF RISER HEIGHT AND EXIT STEAM VOLUME FRACTION ON PERFORMANCE OF NATURAL CIRCULATION BOILING REACTORS. $S=0.12 \mathrm{ln} ., P=2000 \mathrm{lb} / \mathrm{ln} .^{2}$ 


\section{5}
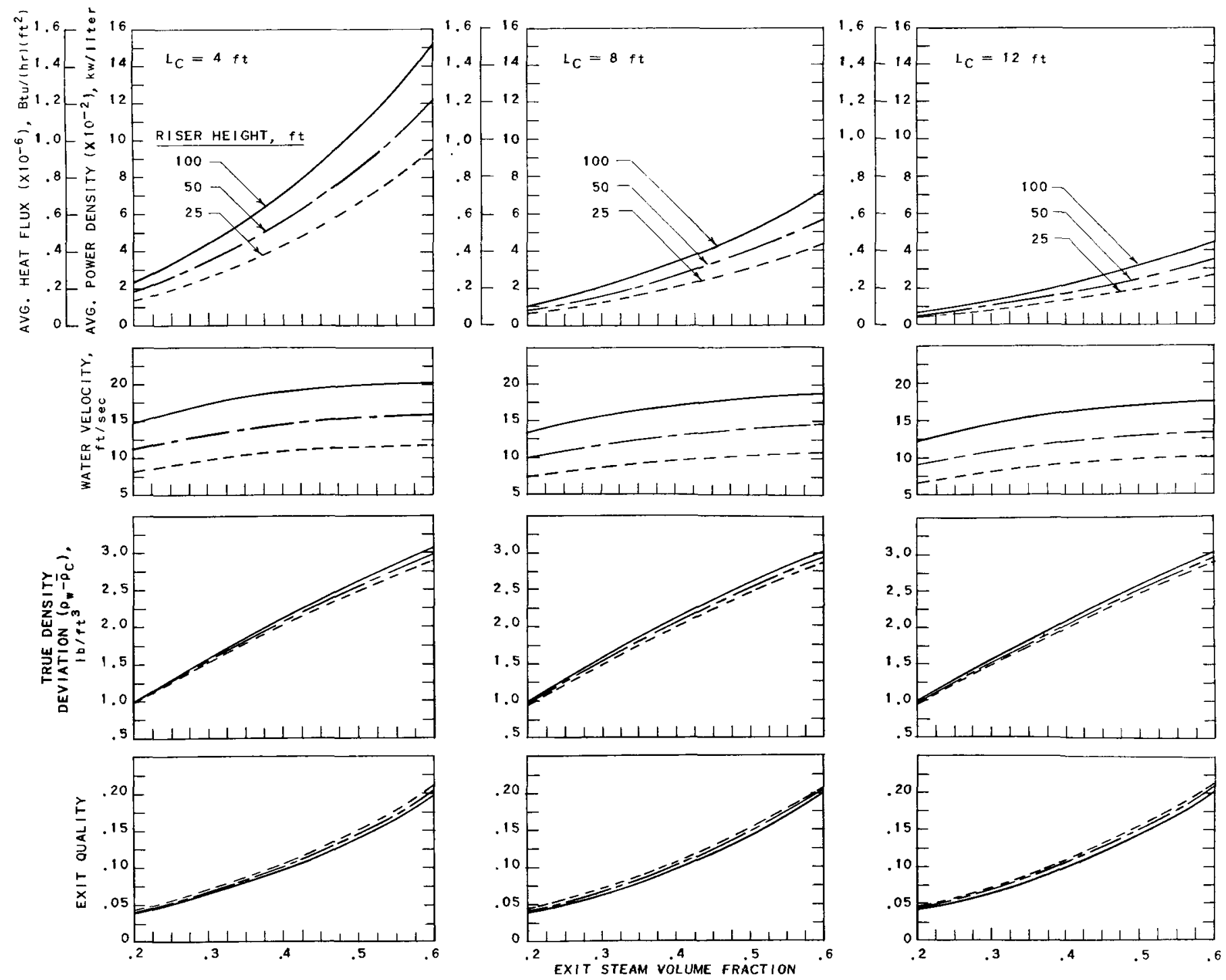

FIG. 21

EFFECT OF RISER HEIGHT AND EXIT STEAM VOLUME FRACTION ON PERFORMANCE OF NATURAL CIRCULATION BOILING REACTORS. $\mathrm{S}=0.25 \mathrm{in}$.; $\mathrm{P}=2000 \mathrm{lb} / \mathrm{in}$ ? 

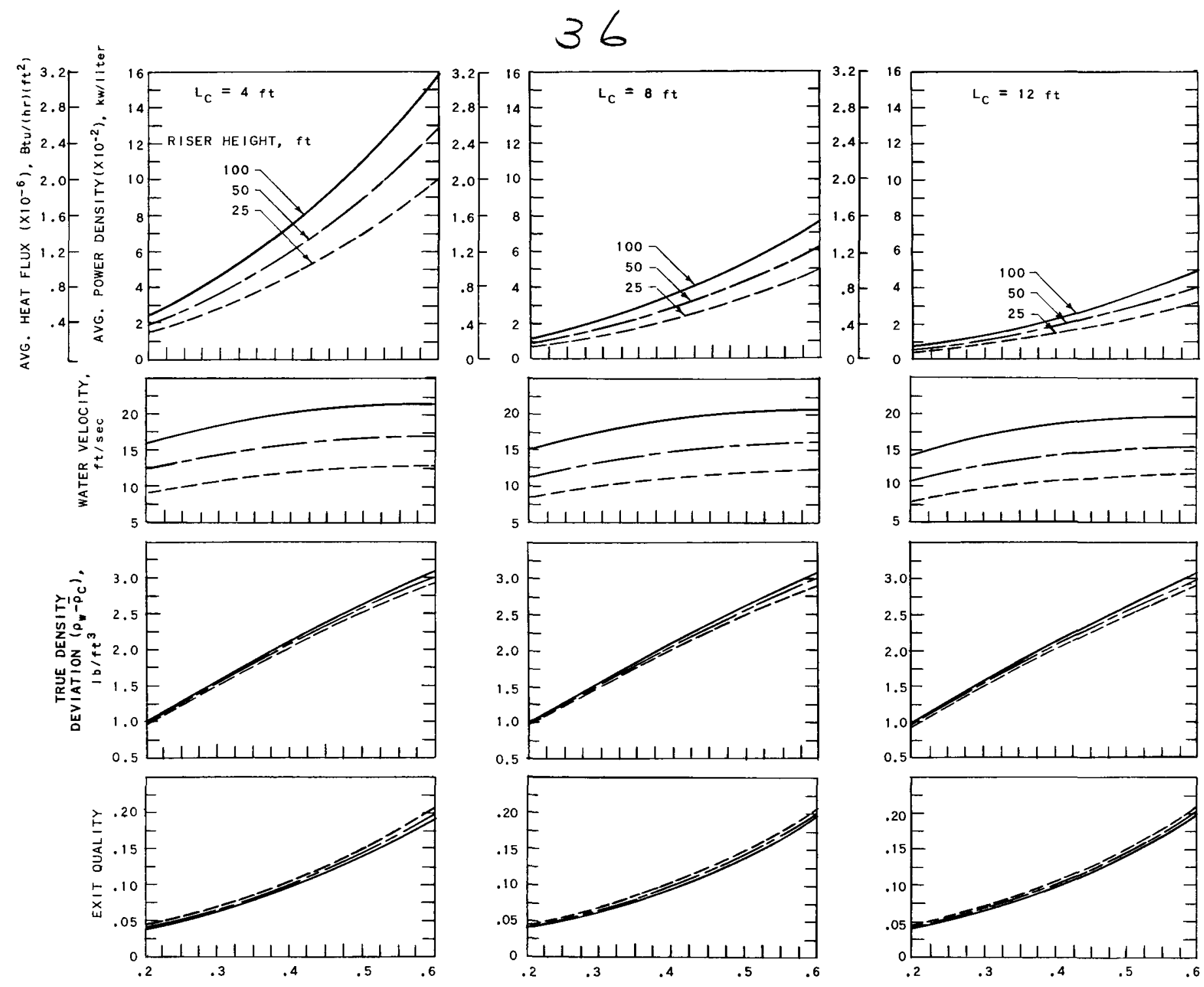

0 0

$0[0=[11+1+11+1$
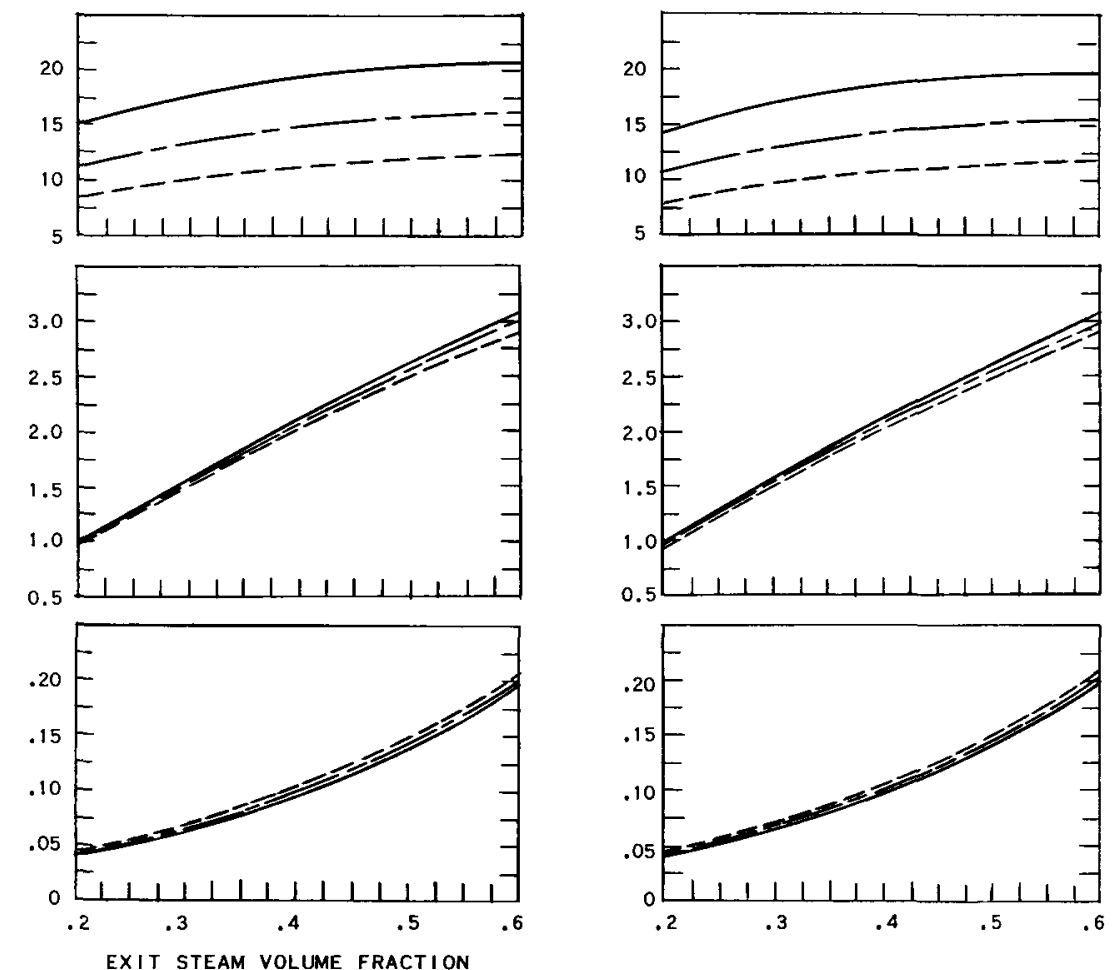

EXIT STEAM VOLUME FRACTION

EFFECT OF RISER HEIGHT AND EXIT STEAM VOLUME FRACTION ON PERFORMANCE OF NATURAL CIRCULATION BOILING REACTORS $S=0.5 \mathrm{in}$; $P=2000 \mathrm{lb} / \mathrm{in}^{2}$ 

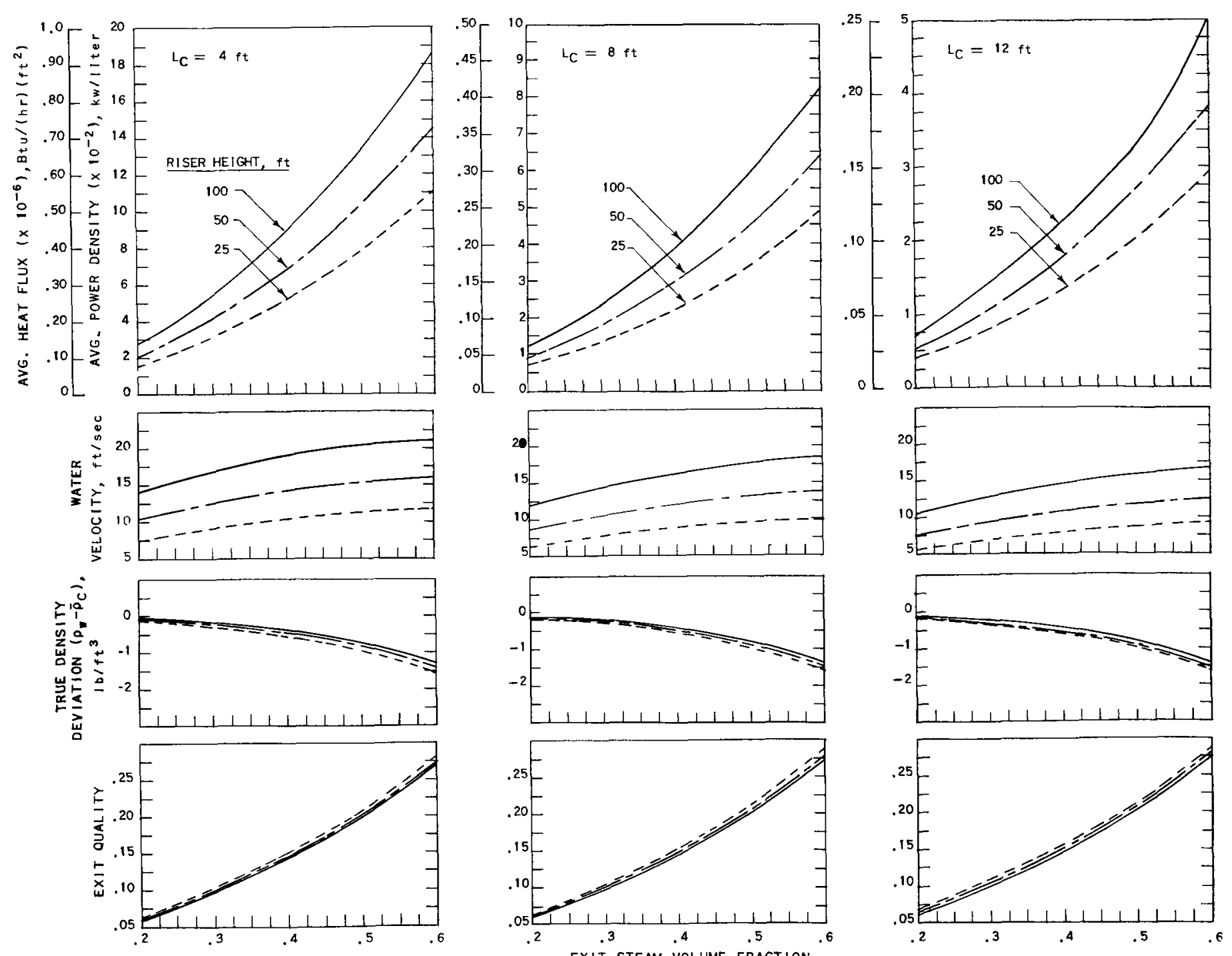

FIG. 23
EFFECT OF RISER HEIGHT AND EXIT STEAM VOLUME FRACTION ON PERFORMANCE OF NATURAL CIRCULATION BOILING REACTORS. $S=0.12 \mathrm{in}$.; $P=2500 \mathrm{lb} / \mathrm{in}^{2}$ 
38
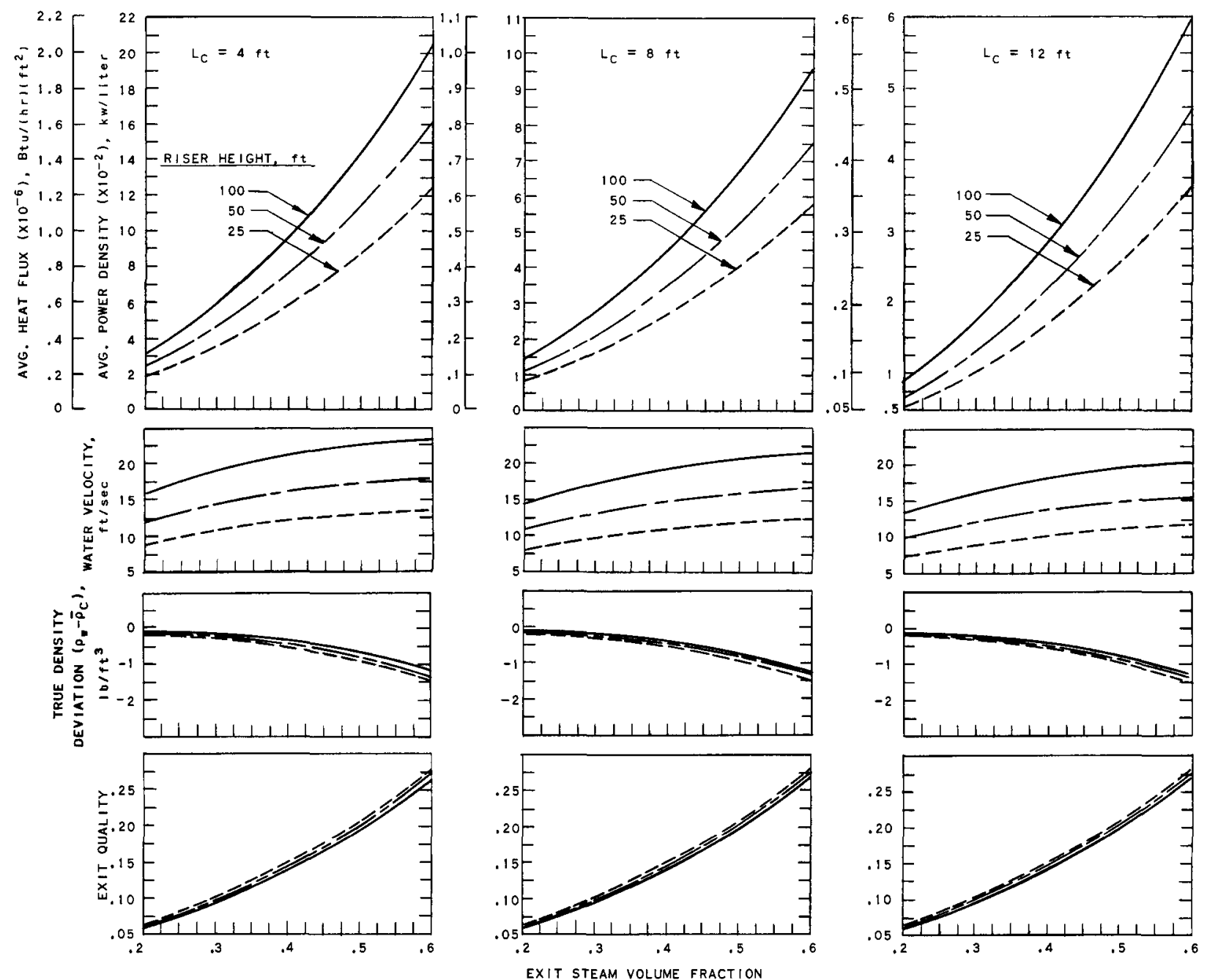

FIG. 24

EFFECT OF RISER HEIGHT AND EXIT STEAM VOLUME FRACTION ON PERFORMANCE OF NATURAL CIRCULATION BOILING REACTORS $S=0.25 \mathrm{in.;} P=2500 \mathrm{lb} / \mathrm{ln}^{2}$ 


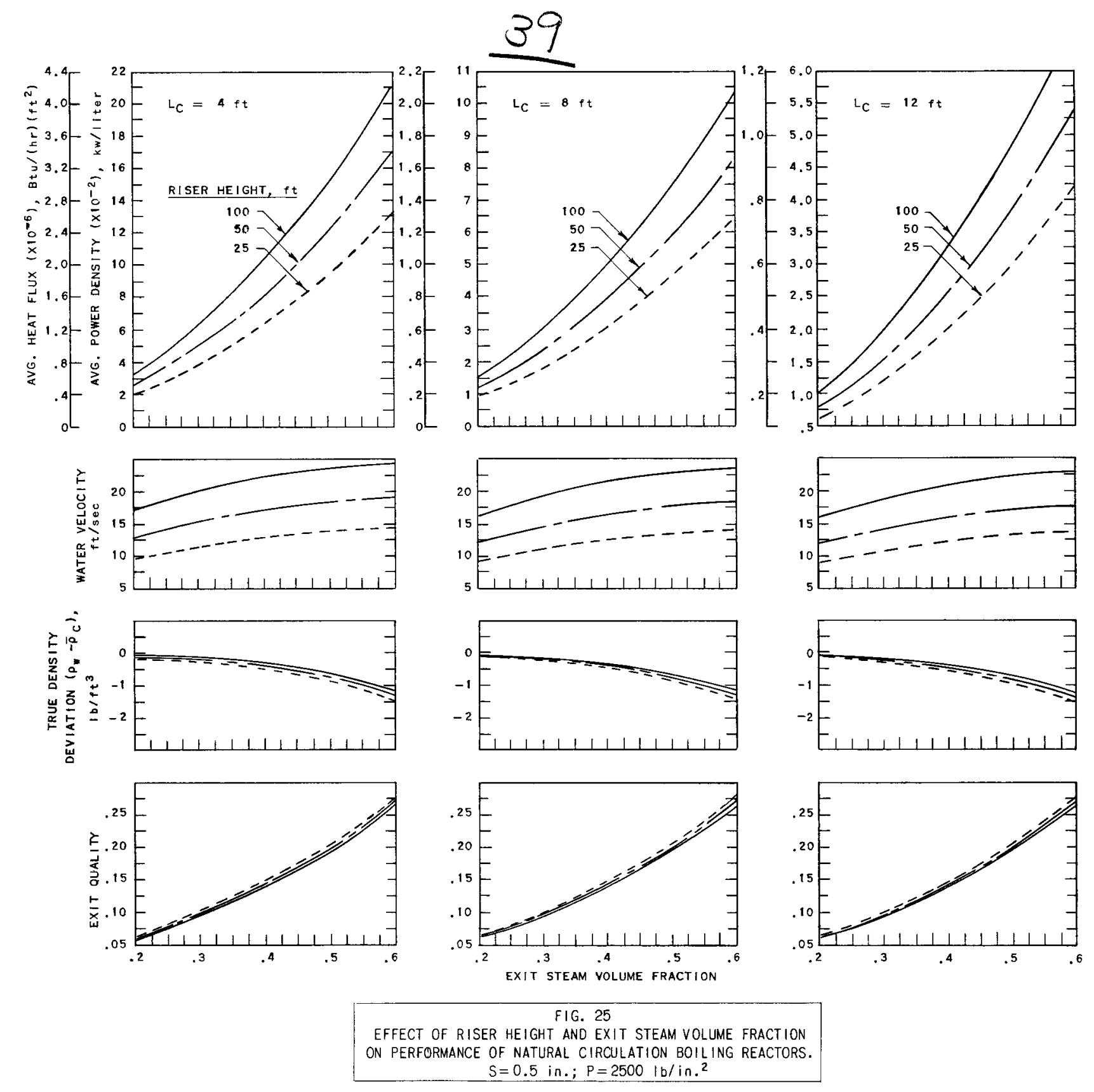



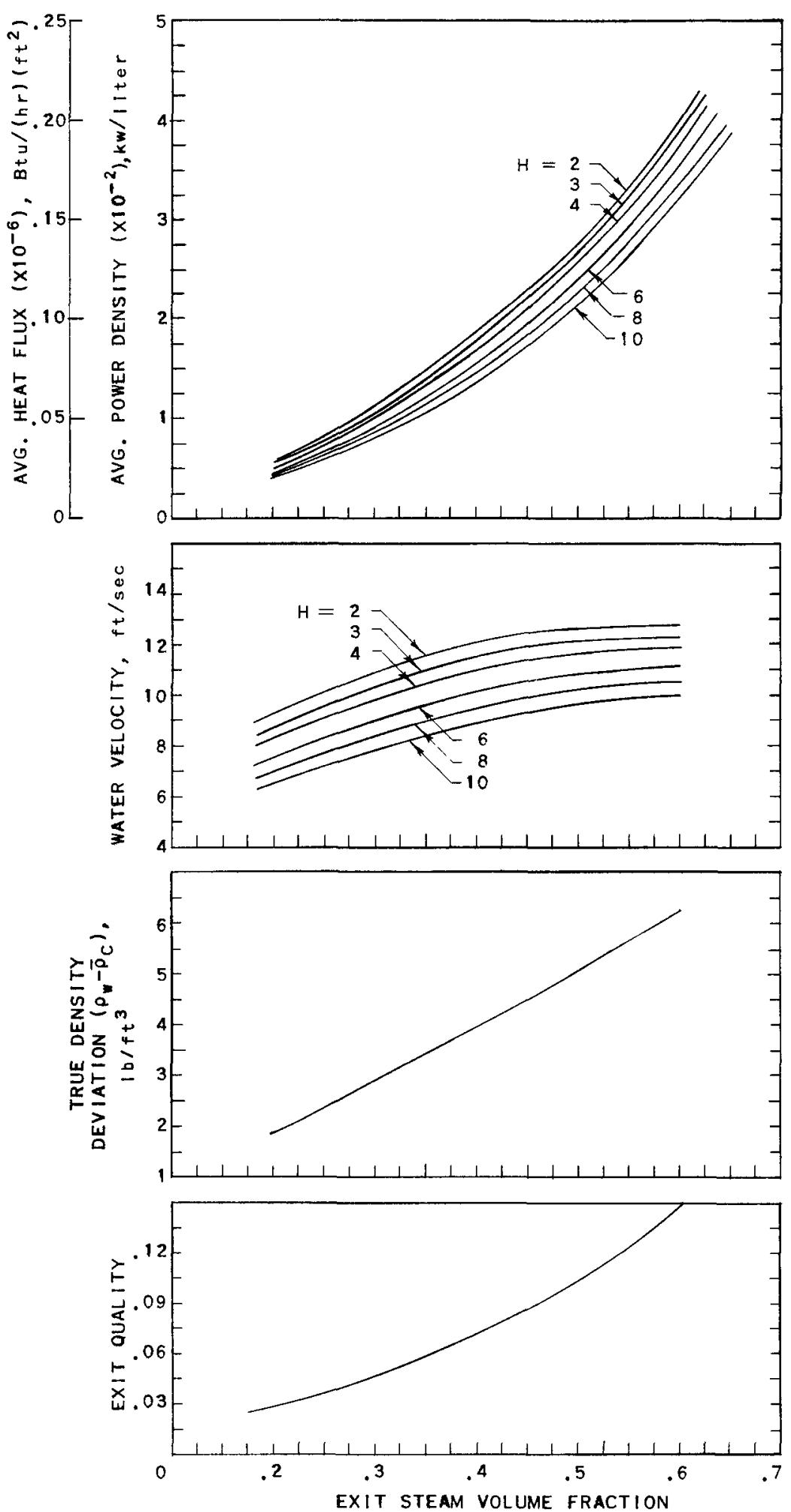

FIG. 26

EFFECT OF EXTERNAL RESISTANCE ON PERFORMANCE OF NATURAL CIRCULATION BOILING REACTORS $P=1500 \mathrm{lb} / \mathrm{in}^{2}{ }^{2} ; L_{C}=8 \mathrm{ft} ; d_{C}=0.04 \mathrm{ft} ; L_{R i}=50 \mathrm{ft}$. 


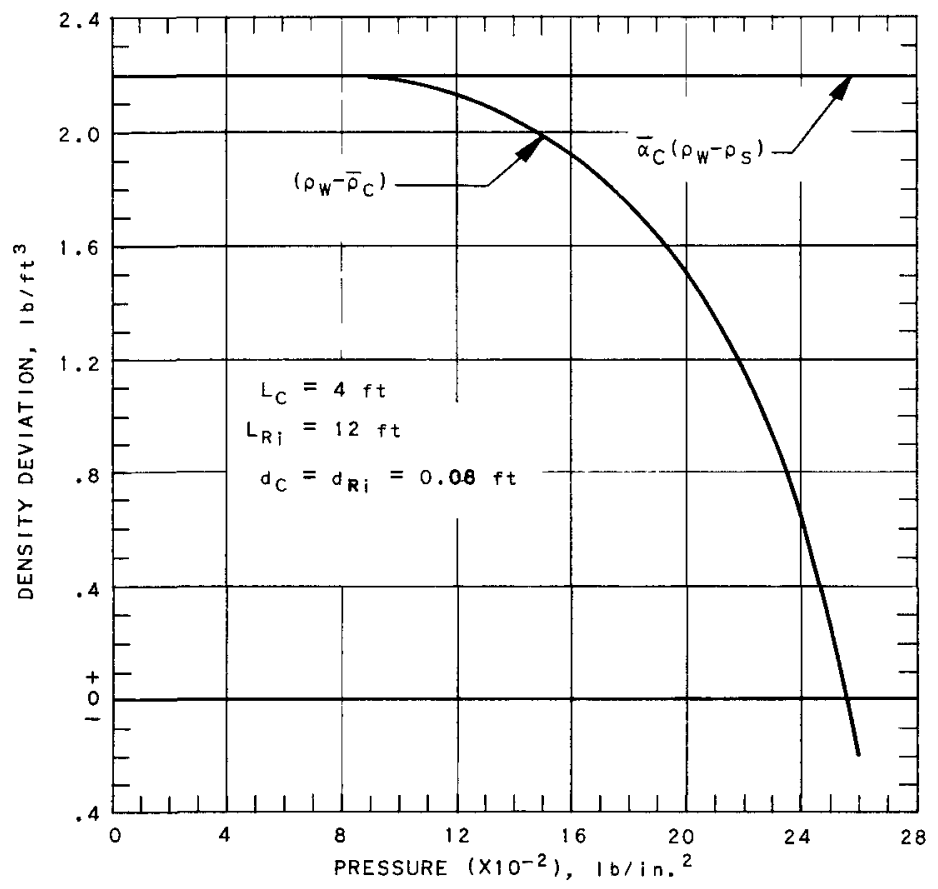

FIG. 27

CHANGE OF TRUE COOLANT DENSITY

DEVIATION WITH PRESSURE FOR

$\bar{\alpha}_{C}\left(\rho_{w}-\rho_{S}\right)=2.2 \mathrm{lb} / \mathrm{ft}^{3}$

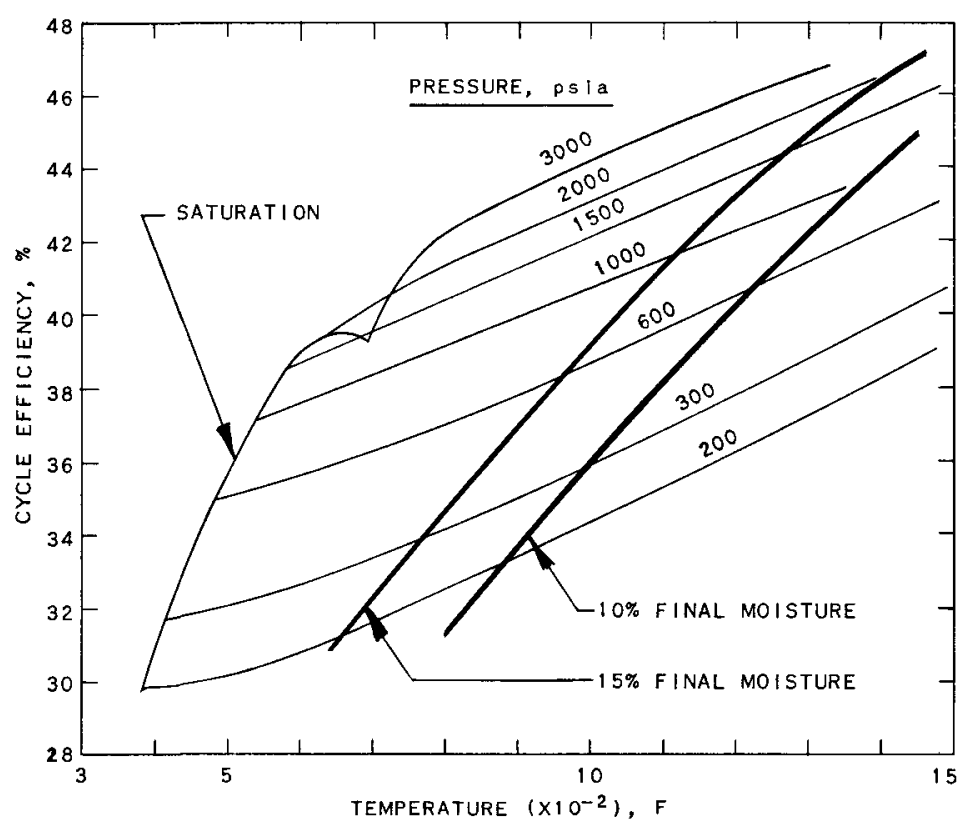

FIG. 28

EFFECT OF TEMPERATURE AND PRESSURE

ON RANKINE CYCLE EFFICIENCY

CYCLE: BOIL AND SUPERHEAT TO $T_{F}$;

EXPAND ISENTROP ICALLY TO

$2^{n} \mathrm{Hg}$ abs. 
42

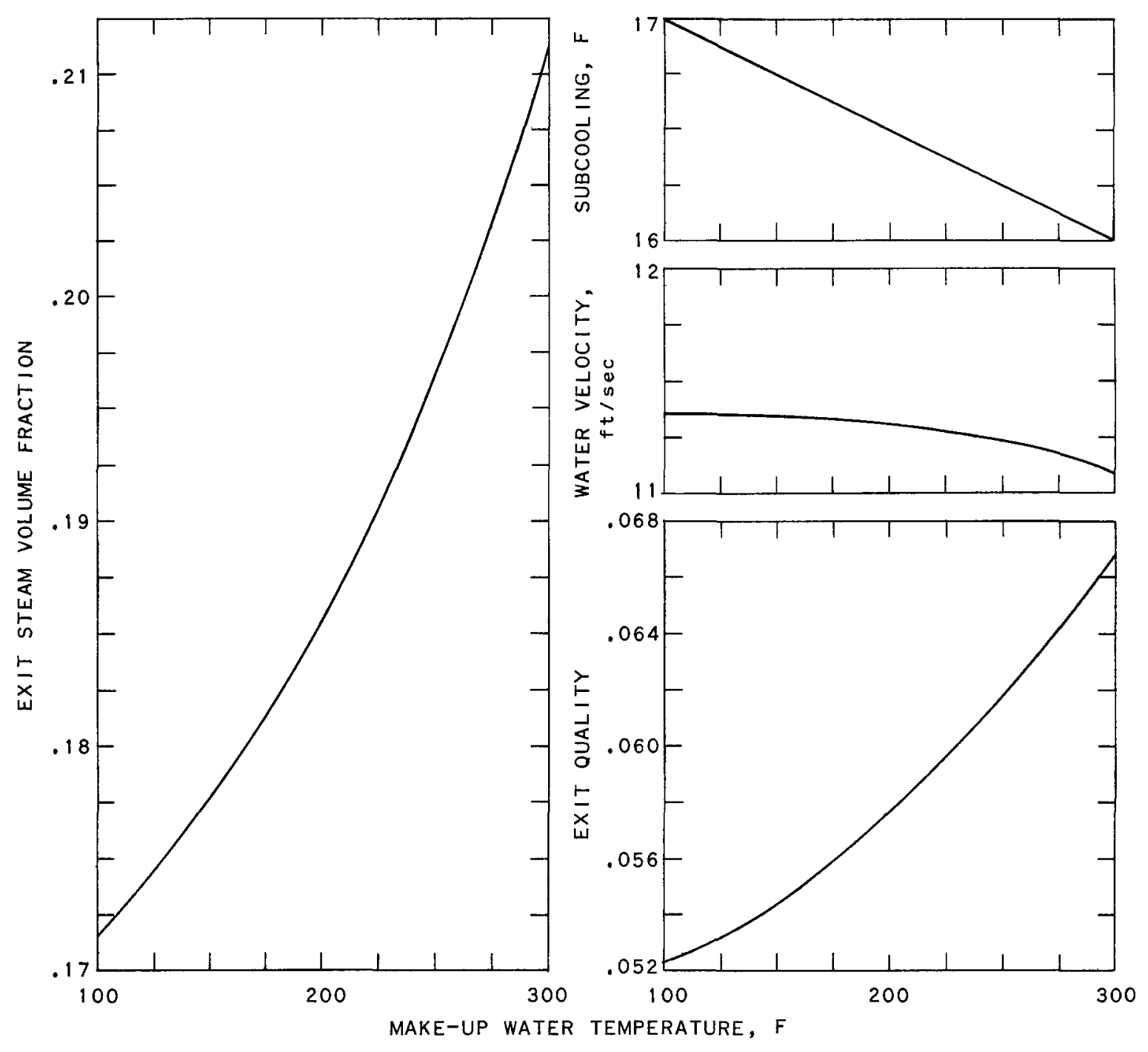

FIG. 29

EFFECT OF MAKE-UP WATER TEMPERATURE ON REACTOR PERFORMANCE 


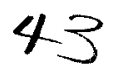

\section{APPENDIX}

\section{METHOD OF ANALYSIS}

The method of analysis used in these studies is that used for general boiling water reactor design at ANL. (1) The results are in good agreement with 150 - 600 psi boiling studies at ANL. Previously developed equations for calculating the circulating water velocity $\left(V_{w}\right)$ for system pressures up to $600 \mathrm{psi}$ did not take into account the effects of subcooling (which become increasingly important at higher pressures), or account for riser core geometry combinations. Therefore, a more general equation has been developed to calculate $\mathrm{V}_{\mathrm{W}}$ :

$$
\frac{\mathrm{v}_{\mathrm{w}}^{2}}{2 \mathrm{~g}}=\frac{\left(1-\frac{\bar{\rho}_{\mathrm{NB}}}{\bar{\rho}_{\mathrm{D}}}\right) \mathrm{L}_{\mathrm{NB}}+\left(1-\frac{\bar{\rho}_{\mathrm{B}}}{\overline{\bar{\rho}}_{\mathrm{D}}}\right) \mathrm{L}_{\mathrm{B}}+\left(1-\frac{\bar{\rho}_{\mathrm{Ri}}}{\bar{\rho}_{\mathrm{D}}}\right) \mathrm{L}_{\mathrm{Ri}}}{\frac{\rho_{\mathrm{w}}}{\bar{\rho}_{\mathrm{D}}}\left\{\mathrm{f}_{\mathrm{D}}\left(\frac{\mathrm{L}_{\mathrm{t}}}{\mathrm{d}_{\mathrm{D}}}\right)\left(\frac{\rho_{\mathrm{w}}}{\bar{\rho}_{\mathrm{D}}}\right)\left(\frac{\mathrm{A}_{\mathrm{C}}}{\mathrm{A}_{\mathrm{D}}}\right)^{2}+\mathrm{f}_{\mathrm{C}}\left[\frac{\mathrm{L}_{\mathrm{NB}}}{\mathrm{d}_{\mathrm{C}}} \frac{\rho_{\mathrm{w}}}{\bar{\rho}_{\mathrm{NB}}}+\overline{\mathrm{R}} \frac{\mathrm{L}_{\mathrm{B}}}{\mathrm{d}_{\mathrm{C}}}\right]+\mathrm{R}_{\mathrm{Ri}}{ }_{\mathrm{Ri}} \frac{\mathrm{L}_{\mathrm{Ri}}}{\mathrm{d}_{\mathrm{Ri}}}\left(\frac{\mathrm{AC}}{\mathrm{A}_{\mathrm{Ri}}}\right)^{2}+\frac{\rho_{\mathrm{w}}}{\bar{\rho}_{\mathrm{D}}}+2\left[\frac{\bar{\rho}_{\mathrm{D}}-\rho_{\mathrm{w}}}{\bar{\rho}_{\mathrm{D}}}+\mathrm{r} \rho_{\mathrm{w}}\right]+\mathrm{H}\right\}}
$$

The factors $\bar{R}$ and $R$ were obtained from either empirical correlations or analytical considerations and are based primarily on singlechannel boiling studies carried out at ANL. Little experimental data have been obtained at ANL for pressures beyond 600 psig. Since a major portion of this study concerns higher pressure regions, recourse has been made to extrapolation of existing correlations and obtaining available information from the literature.

The $\bar{R}$ correlation used is a compromise between the actual data and an analytical $\bar{R}$ function developed at ANL. (2) It is felt that this analytical expression adequately predicts the trend of the pressure effect and is, therefore, used as the basic equation for calculating $\bar{R}$. An additional factor was arbitrarily introduced to correct for the existing difference between actual data and the analytical expression. The factor was made a function of pressure, being 1.30 at 150 psi and becoming 1 at the critical pressure. This $\bar{R}-\alpha$ e relationship is shown in Fig. 30 . The riser friction factor, $R$, was derived in a similar manner and is shown in Fig. 31 . Some corroboration of these $R$ - $\alpha$ relationships for high pressure ranges has been obtained recently by Isbin.(3)

The relationships of $\mathbf{x}$ and $\alpha$ are not fully understood. Various correlations have been developed at ANL (4) that describe these relationships within the range of values normally encountered in reactor design. Although other correlations are more rigorous and accurate, the slip ratio $\left(v_{s} / v_{w}\right)$ - velocity $\left(v_{w}\right)$ correlation has been used for this analysis because of its convenience for calculating. The values of slip ratio at the 
higher pressures and velocities were obtained by extrapolation of existing ANL correlations and data. These extrapolated slip ratio curves, shown in Fig. 32, have been checked in several instances by comparison with fragments of data obtained from other sources. $(3,5)$ Essentially all of the data obtained by ANL is for hydraulic diameters of the active sections of $1 \frac{1}{2}$ in. or less. However, studies made at ORNL ${ }^{(6)}$ for very large hydraulic diameters are in fair agreement with ANL data.

Although scattered fragments of data obtained from several sources have spot checked the extrapolated correlations, it should be kept in mind that these correlations are not completely proven - particularly in the higher pressure and velocity ranges. 


\section{5}
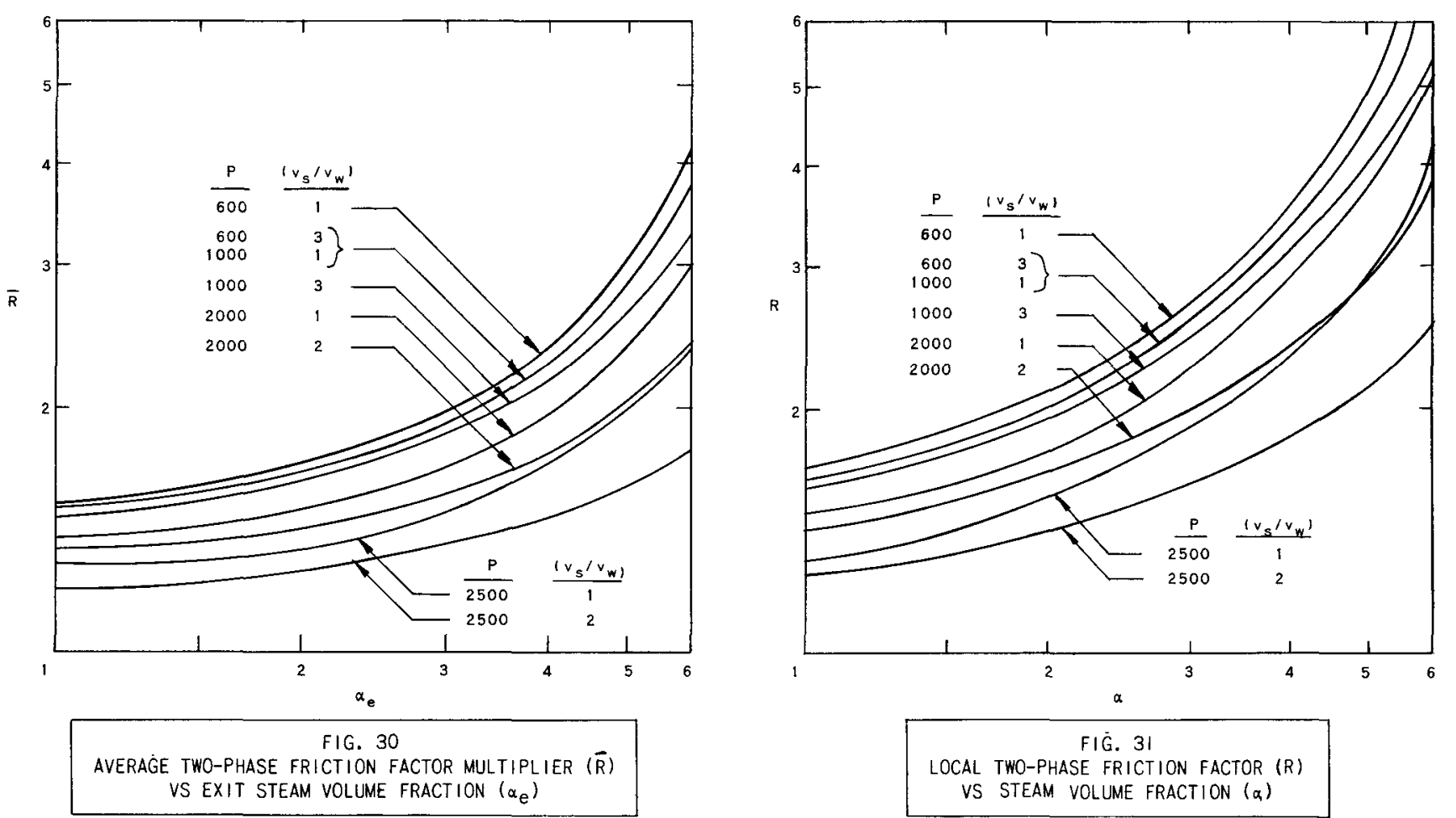

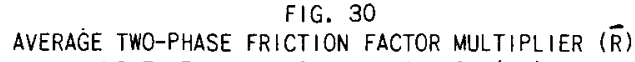
VS EXIT STEAM VOLUME FRACTION $\left(\alpha_{e}\right)$

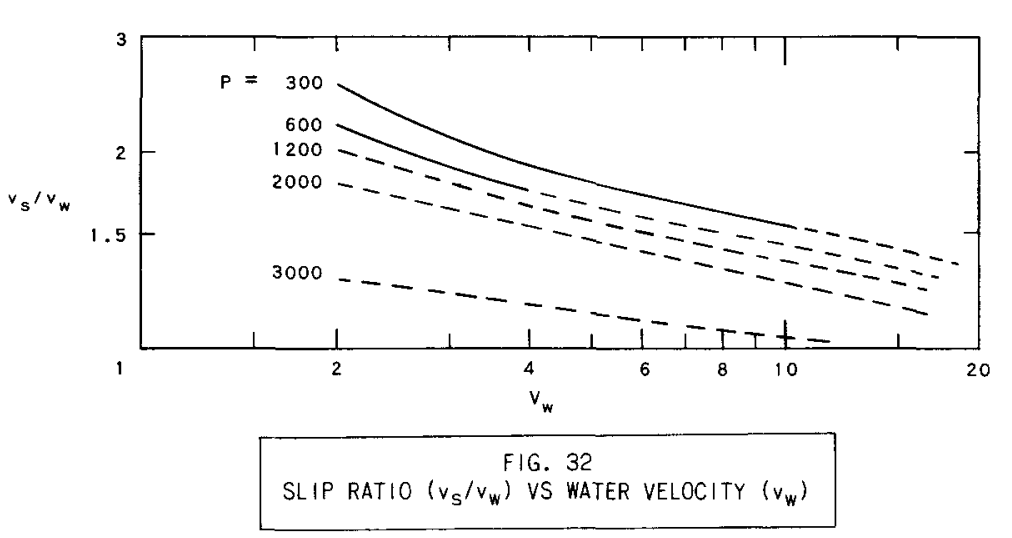




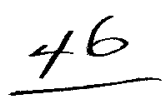

\section{REFERENCES}

1. P. A. Lottes, W. S. Flinn, "Method of Analysis of Natural Circulation Boiling Systems," Nuclear Science and Engineering, Vol. 1, No. 6, December, 1956, pp. 461-476.

2. Reactor Engineering Division Quarterly Report, ANL-5601. December, 1956, pp 36-37.

3. Personal Communication with Prof. H. Isbin, University of Minnesota.

4. P. A. Lottes, et al, "Natural Circulation Boiling Studies," ANL-5735 (to be published).

5. Personal Communication with D. A. Dingoe, Battelle Memorial Institute.

6. P. C. Zmola, R. V. Bailey, "Power Removal from Boiling Nuclear Reactors," ASME Trans. 79, 881-892, 1956.

7. M. Petrick, "Effect of Flow Area Changes on Density of Two-Phase Mixtures," ANL-5787 (to be published).

\section{AC KNOWLEDGEMENT}

The authors are indebted to all members of the Heat Engineering Section who spent considerable time and effort in obtaining the data and correlations used in these studies. Particular thanks are due E. A. Spleha and Dorothy $C$. Jacobson who performed most of the calculations. 